University of Louisville

ThinkIR: The University of Louisville's Institutional Repository

Electronic Theses and Dissertations

$12-2014$

\title{
Avoidance in disordered eating : the roles of overvaluation of weight and shape and repetitive thinking.
}

Anne Christine Bjerg

University of Louisville

Follow this and additional works at: https://ir.library.louisville.edu/etd

Part of the Student Counseling and Personnel Services Commons

\section{Recommended Citation}

Bjerg, Anne Christine, "Avoidance in disordered eating : the roles of overvaluation of weight and shape and repetitive thinking." (2014). Electronic Theses and Dissertations. Paper 1726.

https://doi.org/10.18297/etd/1726

This Doctoral Dissertation is brought to you for free and open access by ThinkIR: The University of Louisville's Institutional Repository. It has been accepted for inclusion in Electronic Theses and Dissertations by an authorized administrator of ThinkIR: The University of Louisville's Institutional Repository. This title appears here courtesy of the author, who has retained all other copyrights. For more information, please contact thinkir@louisville.edu. 


\title{
AVOIDANCE IN DISORDERED EATING: THE ROLES OF OVERVALUATION OF WEIGHT AND SHAPE AND REPETITIVE THINKING
}

\author{
By
}

Anne Christine Bjerg

B.S., Kansas State University, 2009

\begin{abstract}
A Dissertation
Submitted to the Faculty of the College of Education and Human Development of the University of Louisville in Partial Fulfillment of the Requirements for the Degree of
\end{abstract}

Doctor of Philosophy

Department of Education and Counseling Psychology University of Louisville Louisville, Kentucky

December, 2014 

AVOIDANCE IN DISORDERED EATING: THE ROLES OF OVERVALUATION OF WEIGHT AND SHAPE AND REPETITIVE THINKING

\section{By}

Anne Christine Bjerg

B.S., Kansas State University, 2009

A Dissertation Approved on

August 27, 2014

by the following Dissertation Committee:

Patrick Pössel, Dr. rer. soc.

Jesse Owen, $\mathrm{PhD}$

Jeffery Valentine, $\mathrm{PhD}$

Craig Hochbein, $\mathrm{PhD}$ 


\section{DEDICATION}

For doctoral students everywhere.

My thoughts are with you. You will survive. 


\section{ACKNOWLEDGMENTS}

I would like to thank my friends and family for sticking with me.

But, above all, I would like to thank my advisor, Dr. Patrick Pössel, for encouraging me to follow my passions and supporting me every step along the way. 


\section{ABSTRACT \\ AVOIDANCE IN DISORDERED EATING: THE ROLES OF \\ OVERVALUATION OF WEIGHT AND SHAPE AND REPETITIVE THINKING \\ Anne Christine Bjerg}

August 27, 2014

Disordered eating is associated with several negative outcomes and often lead to diagnosable eating disorders. The coping strategies used by those with disordered eating may contribute to such consequences. Past research has found experiential avoidance to be common among those with disordered eating to escape uncomfortable internal experiences. The current study suggested that repetitive thinking and overvaluation of weight and shape are two such mechanisms by which avoidance of negative core beliefs, in particular, is achieved. It was hypothesized that eating disorder symptoms, negative core beliefs, experiential avoidance, overvaluation of weight and shape and repetitive thinking would all be positively and significantly correlated with one another, as measured through Pearson correlation as well as the strength of association in the regression paths via Structural Equation Modeling (SEM). Further it was hypothesized that the variables as a whole would have significant model fit, indicating that repetitive thought and overvaluation of weight and shape would be two mechanisms by which those with disordered eating avoid negative core beliefs.

A total of 344 participants were recruited for this cross-sectional study from offline, online, community, and clinical sites nation-wide; 244 were included in the final 
sample. The majority of this final sample identified as female (84.8\%), White (88.1\%), are from the US South (63.1\%), and were recruited through the community $(80.3 \%)$. The data were assessed using SEM in order to provide a more reliable measure of assessing how the variables interact as a whole.

Results indicated that the study's first hypothesis was met - the variables were all significantly and positively correlated with one another at the $p<.001$ level. The strength of associations in the regression paths were also positive and significant, with small to large effect sizes. However, the hypothesized model was not a significant fit to the data, and it is possible that the participants' retrospective recall of their repetitive thoughts and the potential omission of a significant moderating variable led to the model not achieving a better fit. Overall, the study possesses significant strengths through its variability in sample (i.e., including clinical and non-clinical as well as female and nonfemale participants) and exploratory examination of how the variables relate to one another. It is recommended that future studies continue to explore these relationships to determine how those with disordered eating cope with their negative core beliefs through avoidance and what interventions can be developed to assist in recovery. 
TABLE OF CONTENTS

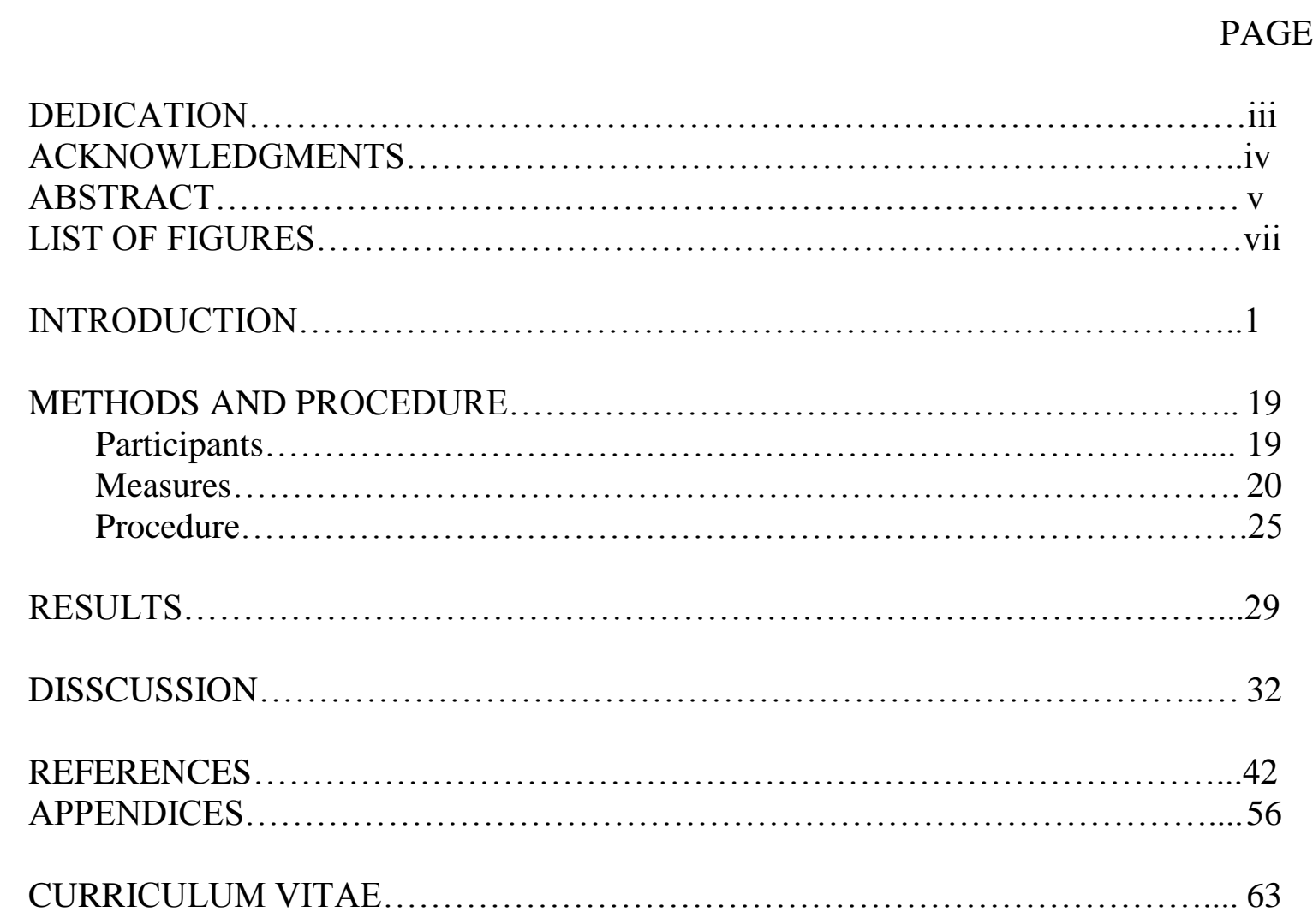




\section{LIST OF FIGURES}

$\begin{array}{lll}\text { FIGURE PAGE } & \text { PA }\end{array}$

1. Cognitive Model (adapted form J. S. Beck, 2011).............................5

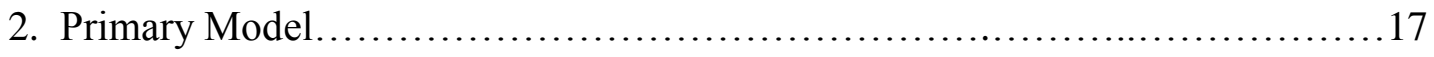

3. Alternative Model.....................................................27

4. Eating Disorder Core Beliefs CFA.................................... 31

5. Standardized Regression Weights of Primary Model..........................32

6. Standardized Regression Weights of Alternative Model........................33 


\section{INTRODUCTION}

Disordered eating and body dissatisfaction among the general population is high. Allaz, Bernstein, Rouget, Archinard, and Morabia (1998) found 71\% of women wanted to lose weight even though $73 \%$ of this subsample was at normal weight. Further, $59 \%$ of adolescent and young adults have reported skipping meals to lose weight, and $36.7 \%$ report eating less than 1,200 calories per day for the same purpose (Tylka \& Subich, 2002). Dissatisfaction with one's body often leads to subsyndromal eating disorders, or disordered eating, which encompasses many of the behaviors found in clinical eating disorders but does not result in the same severity of distress. Though not all who exhibit disordered eating go on receive a diagnosable eating disorder, those who are exposed to others partaking in maladaptive weight loss strategies are more likely to partake in similar behaviors and may later develop more severe eating disorders (Stice, 1998).

Eating disorders are commonly defined at the symptom level using the Diagnostic and Statistical Manual of Mental Disorders, fourth edition, text revision (DSM-IV; American Psychiatric Association, 2000), which currently recognizes three eating disorders - anorexia nervosa, bulimia nervosa, and eating disorder not otherwise specified (EDNOS).

\section{Anorexia Nervosa (AN)}

$\mathrm{AN}$ is primarily characterized by extremely low body weight $(\mathrm{BMI}<18.5$

$\mathrm{kg} / \mathrm{m}^{2}$ for adults; BMI below the $10^{\text {th }}$ percentile for children and adolescents), and an 
intense fear of gaining weight or becoming fat. Further, AN often involves a failure to acknowledge the seriousness of one's emaciation. Those with AN tend to have severe body distortions in which one's body shape is perceived incongruent to how it actually

exists, leading one to believe s/he is weightier than in reality. Overvaluation of weight or shape is also found in those with AN where self-worth is predominantly gauged off bodily appearance.

\section{Bulimia Nervosa (BN)}

Periods of binge eating followed by compensatory behaviors to prevent weight gain (e.g., excessive exercise, purging, misuse of laxatives, etc.) characterize BN. Those with BN are typically of average weight and, similar to those with AN, overvalue their weight and shape, using their appearance as a primary means of selfevaluation. $\mathrm{BN}$ is currently separated into two specifying types, purging (misuse of laxatives or self-induced vomiting) and non-purging (no use of vomiting or laxatives but engagement in fasting or compulsive exercise). However, it is expected that these specifiers will be removed in the DSM-V due to a lack of research on the non-purging subtype and its general resemblance to binge eating disorder (Van Hoeken, Veling, Sinke, Mitchell, \& Hoek, 2009).

\section{Eating Disorder Not Otherwise Specified (EDNOS)}

EDNOS is the most commonly diagnosed eating disorder, comprising $60 \%$ of eating disorder outpatient clients (Fairburn \& Bohn, 2005). The high prevalence of EDNOS is not due to mis-diagnosis but to high variance in symptom presentation. Those with EDNOS should not be thought of as having a "less severe" disorder. For 
example, Fairburn, Cooper, Bohn, O’Connor, Doll, and Palmer (2007) found those with EDNOS to have severity levels similar to those with BN. In fact, the majority of those with an EDNOS diagnosis present with subthreshold AN or BN, meeting all diagnostic criteria but one, suggesting that the EDNOS diagnosis is a mere variant of the primary eating disorders (Turner \& Bryant-Waugh, 2004).

The acceptable DSM-IV EDNOS diagnoses are those in which an individual: (a) meets all criteria for AN expect amenorrhea, or (b) weighs within the normal range, (c) meets all criteria for $\mathrm{BN}$, but the frequency of binge/purge episodes is less than 2 times per week or has been occurring for less than 3 months, (d) uses of compensatory behaviors after eating a small amount of food (i.e., purging disorder), (e) chews and spits out large amounts of food without swallowing, or (f) binges without using of compensatory behaviors (i.e., binge eating disorder).

Binge Eating Disorder (BED) is the most recognized EDNOS subtype and has received substantial research attention despite not being a unique DSM diagnosis (for review see Wonderlich, Gordon, Mitchell, Crosby, \& Engel, 2009). BED has historically been compared to non-purging BN (e.g., Fichter, Quadflieg, \& Hedlund, 2008) and obesity; however, researchers have found that the characteristics of binge eating support its status as a unique entity (Devlin, Goldfein, \& Dobrow, 2003). Its inclusion in the upcoming DSM-V has been recommended (Striegel-Moore \& Franko, 2008).

\section{Consequences of Disordered Eating and Eating Disorders}

Lifetime prevalence rates for eating disorders have been reported at $0.3 \%$ for AN, $0.9 \%$ for BN, and $1.6 \%$ for BED (Swanson, Crow, Le Grange, Swendsen, \& 
Merikangas, 2011). Though these rates may be lower than those of other psychological disorders, they by no means indicate that eating disorders are less severe. Klump, Bulik, Kaye, Treasure, and Tyson (2009) have advocated for their classification as serious mental illnesses due to their biological correlates and impact on daily functioning. Eating disorders have among the highest mortality rates of any psychological disorder (Arcelus, Mitchell, Wales, \& Nielsen, 2011). This results from the numerous physical complications associated with eating disorders including, but not limited to, cardiac arrhythmia, metabolic alkalosis, loss of cardiac muscle, immune dysfunction, muscle weakness, congestive heart failure, stunted growth, osteopenia, amenorrhea, hypothermia, hypotension, dental enamel erosion, esophagitis, gastric ruptures, and atrophy of the pituitary gland (Katzman, 2005; Mitchell \& Crow, 2006; Rome \& Ammerman, 2003) - and from an increased risk for suicide among individuals with eating disorders. Three percent to $20 \%$ of those with $\mathrm{AN}$ and $25 \%$ to $35 \%$ of those with $\mathrm{BN}$ have reported making a suicide attempt at some point in their lives (Franko \& Keel, 2006), while the lifetime prevalence of suicide attempts in the general population is $2.7 \%$ (Nock \& Kessler, 2006).

Similarly, disordered eating has shown to contribute to suicidal ideation (Brausch \& Gutierrez, 2009) and self-harming behaviors (Tam, Ng, Yu, \& Young, 2007).

\section{Cognitive Theory and Eating Disorders}

According to cognitive theory (J. S. Beck, 2011), individuals' ways of thinking can be broken down into three levels: automatic thoughts, intermediate beliefs, and core beliefs (Figure 1). Automatic thoughts are surface level cognitions that are triggered in response to relevant situations. These thoughts are not always 
functional or realistic. For example, after eating a slice of cake, an individual may have the automatic thought that s/he will now gain a significant amount of weight and is "fat." Intermediate beliefs are on the second level and are made up of attitudes (e.g., "it's terrible to be fat"), rules (e.g., "stop eating if I start to gain weight"), and assumptions (e.g., "no one will like me if I'm fat, but if I'm thin, I'll be loved). Both automatic thoughts and intermediate beliefs are

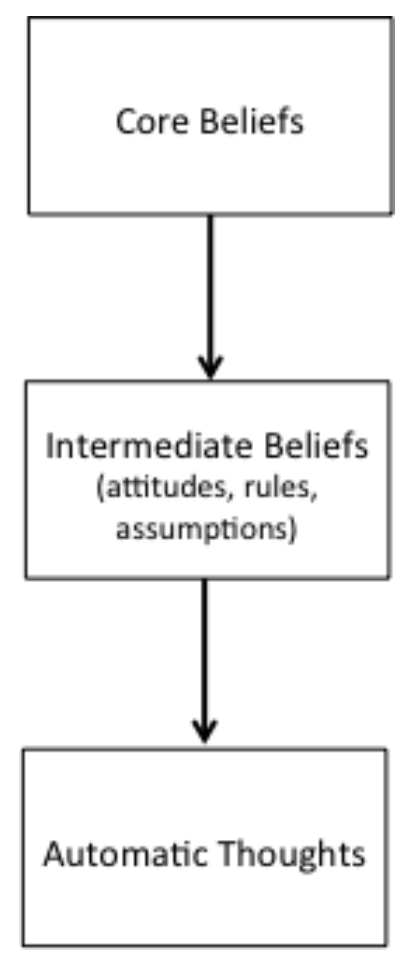

Figure 1. Cognitive Model (adapted from J. S. Beck, 2011)

developed in response to core beliefs. Core beliefs comprise the deepest level of cognition, and consist of rigid, overgeneralized beliefs. These beliefs are the individual's fundamental understanding of the way the world works and how things simply "are" (J. S. Beck, 2011). Core beliefs about the self begin to develop at an early age; experiencing negative or even traumatic events promotes dysfunctional 
beliefs about the self (e.g., "I am helpless", "I am unlovable"; Cooper, Wells, \& Todd, 2004). It is not uncommon for those with eating disorders to hold deep-rooted core beliefs that they are powerless, failures, defective, unattractive, worthless, or empty (Woolrich, Cooper, \& Turner, 2006). The current study hypothesizes that individuals with high levels of disordered eating adopt avoidant strategies in order to cope with such distressing core beliefs.

\section{Eating Disorders and Experiential Avoidance}

It has been suggested that eating disorders are functional means of controlling distressing internal experiences (Schmidt \& Treasure, 2006; Slade, 1982; Wildes, Ringham, \& Marcus, 2010). This control may be presented by manipulating the intensity, frequency, or duration of private memories, cognitions, emotions, or sensations - what Hayes, Wilson, Gifford, Follette, and Strosahl (1996) term experiential avoidance. At the most basic level, positive correlations have been found among eating disorders and experiential avoidance (Cowdrey \& Park, 2012; Hayaki, 2009; Rawal, Park, \& Williams, 2010). Those with eating disorders also tend to engage in avoidant coping strategies (Aldao, Nolen-Hoeksema, \& Schweizer, 2010) and have high harm-avoidant personalities (Fassino, et al., 2002), meaning they tend to avoid punishment rather than seek reward. This suggests that avoidance of distress is a common strategy for those with eating disorders. Disordered eating behaviors have also shown relationships with avoidance. For example, Spoor, Bekker, Van Strien, and van Heck (2007) found avoidance to be positively associated with emotional eating (i.e., overeating in response to negative affect) among community and clinical samples. 
Eating disorders themselves have even been conceptualized as a mechanism by which painful experiences are avoided. Schmidt and Treasure's (2006) cognitiveinterpersonal model of AN includes experiential avoidance as a primary maintenance factor, suggesting that $\mathrm{AN}$ is an adaptive, though not healthy, defense against interpersonal confrontations, uncomfortable emotions, and closeness to others. This interpretation is supported by a study which found that those with AN believe a positive aspect of their eating disorder is that it allows them to feel more structured, safe, and special and it gives them a way to communicate their emotions. For those with $\mathrm{BN}$, their eating disorder allows them to eat but still maintain control over how they look and relieves the boredom and emptiness in their lives. Most notably, both groups report that their eating disorder allows them to stifle emotions (Gale, Holliday, Troop, Serpell, \& Treasure, 2006). The eating disorder, therefore, serves the adaptive function of allowing the individual to avoid experiencing feelings that may be associated with discomfort.

Avoidance may also be triggered in response to distressing core beliefs. Woolrich, Cooper, and Turner (2006) discovered that the majority of those with AN endorse restricting food, pleasing others, and engaging in obsessions in order to cope with negative self-beliefs. A recent cognitive theory of eating disorders (Waller, submitted, as cited in Luck, Waller, Meyer, Ussher, \& Lacey, 2005) incorporates the schematic processes that occur when one's core beliefs are triggered. Because dysfunctional beliefs are naturally associated with distressing emotions, those with eating disorders are theorized to engage in avoidant strategies to prevent or escape such feelings. Restrictive eating is associated with schema compensation, or the 
adoption of behaviors and attitudes that are directly opposite of one's schema in order to prevent the beliefs from being triggered. Bulimic symptoms are associated with schema avoidance - engagement in various thoughts, feelings, or behaviors that allow the individual to escape or reduce the negative feelings that occur after the schema has been triggered. Waller terms this primary avoidance of affect and secondary avoidance of affect, respectively. In other words, schema avoidance can either be accomplished by preventing the schema from being triggered (i.e., primary avoidance) or preventing the self from feeling the schema after it has been triggered (i.e., secondary avoidance).

Regardless of whether the method is primary or secondary avoidance, it is clear that those with eating disorders adopt strategies to escape, control, or avoid distressing core beliefs. In other words, negative core beliefs can trigger avoidant behaviors. Though an avoidant coping strategy is adaptive in the short term, it is associated with numerous negative consequences. For example, a recent literature review found higher levels of experiential avoidance to influence substance use relapse, mediate the relationship between traumatic experiences and psychological distress, predict the severity of various anxiety disorders, and mediate the relationship between maladaptive coping skills and psychological distress (Chawla \& Ostafin, 2007). The current study hypothesizes that overvaluation of weight and shape and repetitive thinking are two mechanisms by which those with eating disorders can avoid negative core beliefs. 


\section{Overvaluation of Weight and Shape}

Fairburn (2008) proposes that the dysfunctional use of weight and shape as a primary means of self-evaluation is at the core of eating disorder psychopathology. This overvaluation of weight and shape significantly contributes to the severity of one's distress (Grilo, Masheb, \& White, 2010), and higher levels of overvaluation negatively predict treatment outcomes (Masheb \& Grilo, 2008). Significant overvaluation is currently a criterion for both $\mathrm{AN}$ and $\mathrm{BN}$ diagnoses (APA, 2000) and has also been found among those with BED (Goldschmidt et al., 2010). Those who engage in disordered eating are heavily preoccupied with thoughts about food, weight and shape. For example, Sunday, Halmi, and Einhorn (1995) found $42 \%$ of those with eating disorders spend more than eight hours per day thinking about their body, exercise, food, and eating while $72 \%$ spend at least three hours per day with such thoughts. Further, 37\% report they were unable to last even one hour without thinking about food, weight, or body shape. Spending such long amounts of time thinking about these topics likely results in less time spent thinking about life tasks (e.g., daily work activities). In other words, it is likely that this preoccupation results allows the individual to avoid dealing with his or her current reality.

It is probable that negative core beliefs lead to the development of overvaluing body weight and shape, which can be conceptualized as an intermediate belief. For example, individuals may believe that controlling physical appearances allows for more control over the environment (e.g., "If I look thin, others will like me and I will be able to get what I want in life"). This may create an assumption that being thin and in control of their body allows them to be loved and accepted by others. 
Alternatively, the individual may hold an attitude in which being "fat" is unacceptable, thereby creating the rule that one must always be thin lest they be considered unacceptable as a person.

Placing undue focus and value on one's appearance can be the individual's way to cope with negative thoughts, feelings, and events as well as a means of avoiding or masking the heart of their distress - their core beliefs and experiences. Polivy and Herman (1999) found empirical support for this masking of distress hypothesis. In their study, individuals with disordered eating tended to attribute negative affect to the fact that they ate ice cream earlier in the day rather than the fact that they more recently failed at solving a series of anagrams. In other words, it felt safer to feel upset because of violating a diet than to feel upset because of failing.

Overvaluation of weight and shape may be the intermediate belief created by the individual in order to cope with their negative core beliefs. In addition to such compensatory beliefs, it is also possible that specific cognitive processes, such as repetitive thinking, may be involved in how an individual avoids connecting with the personal meaning of their core beliefs.

\section{Repetitive Thoughts}

Previous research on cognition has largely focused on differential effects of specific types of thinking. A.T. Beck (1976) theorized that the specific content of one's thoughts discriminates between types of emotional distress (content specificity hypothesis). In this way, psychologists have most often focused on the associations between worry and anxiety as well as cognitive rumination and depression.

Cognitive rumination - hereafter to be termed rumination - is a process involving 
prolonged, intense, and passive thoughts about causes and consequences of negative affect (Nolen-Hoeksema, 1991; Nolen-Hoeksema, Wisco, \& Lyubomirsky, 2008). Worry has been defined as "an attempt to engage in mental problem-solving on an issue whose outcome is uncertain but contains the possibility of one or more negative outcomes" (Borkovec, Robinson, Pruzinsky, \& Depree, 1983, p. 9). Excessive worry is currently a criterion for Generalized Anxiety Disorder (APA, 2000), and rumination influences both the onset (Just \& Alloy, 1997) and maintenance (NolenHoeksema, Morrowm \& Fredrickson, 1993) of major depressive episodes.

However, recent trends in cognitive research have suggested that there may also be significant, underlying similarities among different types of thinking. For example, Watkins, Moulds, and Mackintosh (2005) found ruminative thoughts and worry thoughts to have more similarities than differences. Although worry and rumination were found to be more future-focused and more past-focused, respectively, they were similar along 31 other dimensions including frequency, personal importance, and interference with functioning. Therefore, even though a difference in the time-orientation for types of thoughts exists, it does not relate to differences in resulting distress; it is unlikely that differences in the content of various types of thought translate into practical differences. Further, worry is not limited to anxiety, and rumination is not limited to depression. McLaughlin and NolenHoeksema (2011) found rumination to mediate the relationship between current depressive symptoms and future anxiety as well as current anxious symptoms and future depression. Worry and rumination have also shown associations with other forms of distress, including eating disorders (Aldao \& Nolen-Hoeksema, 2010; Alado, Nolen-Hoeksema, \& Schweizer, 2010; Nolen-Hoeksema, Stice, Wade, \& 
Bohon, 2007; Sassaroli, Bertelli, Decoppi, Crosina, Milos, \& Ruggiero, 2005). In sum, numerous studies have failed to uphold Beck's (1976) content specificity hypothesis regarding types of thinking.

Because practical differences between specific types of thinking may not exist, it may be more helpful to It is likely that the concept of repetitive thinking, defined as the "process of thinking attentively, repetitively or frequently about one's self and one's world" (Segerstrom, Stanton, Alden, \& Shortridge, 2003; p. 909), plays a significant role in the maintenance of psychological disorders. Repetitive thinking includes specific types of thought, such as worry and rumination, each of which are differentiated by the specifics of what an individual thinks about. However, this construct is broadly defined and is also concerned with patterns and processes, or how one thinks.

Watkins (2008) reviewed the constructive and unconstructive features of repetitive thinking, emphasizing the underlying processes of these thoughts. Types of repetitive thought (including rumination and worry) can be best categorized along two dimensions: (a) valence of the thought content - positive or negative, and (b) construal adopted while thinking - concrete or abstract. Segerstrom, Stanton, Alden, and Shortridge (2003) used multidimensional scaling and found similar valence and construal, or what they termed purpose, dimensions. Depending on the combination of these dimensions, repetitive thinking can result in constructive or unconstructive consequences.

Valence. 
Valence represents the structural component of repetitive thinking and describes the thoughts' overall tone, whether positive or negative (Watkins, 2008). Essentially, valence represents whether one is thinking about positive themes or negative themes. Watkins (2008) provides a review on how valence may affect overall outcomes.

Thinking positively, especially after experiencing minor, adverse events (O'Mara, McNulty, \& Karney, 2011) tends to result in positive outcomes, such a reduction in depressive symptoms. Yet, those experiencing more significant adverse events can also profit from positive thinking. For those diagnosed with a chronic medical illness, finding benefit in their disease helps to buffer against negative emotional reactions to their health and promotes psychological well-being (Tran, Weibe, Fortenberry, Butler, \& Berg, 2011). Finding benefit requires the individual to think with positively valenced thoughts even when experiencing negative or stressful events. Self-affirmations (Steele, 1988) can also lead to constructive outcomes. Not only do self-affirmations help to improve one's self-esteem and decrease ruminative thoughts (Koole, Smeets, van Knippenberg, \& Dijksterhuis, 1999), but they are also associated with greater body satisfaction in adolescents (Armitage, 2012).

Conversely, thoughts consisting of negative content are associated with higher levels of anxiety and worse overall mental health (Segerstrom et al., 2003). Thinking about a negative event with negative thoughts or reappraising a positive event negatively can prolong the negative emotions and shorten positive emotions, respectively (Verduyn, Van Mechelen, \& Tuerlindckx, 2011). Ronan and Kendall 
(1997) found those with higher levels of emotional distress (anxiety and depression) displayed more negative cognitions than those without significant emotional distress. Overall, repetitive negative thinking, like rumination and worry, has shown strong associations with clinical levels of depression, anxiety, anger, shame, general psychological distress, social phobia, obsessive compulsive disorder, insomnia, and hypochondriasis (Ehring, Zetsche, Weidacker, Wahl, Schönfeld, \& Ehlers, 2011; McEvoy, Mahoney, \& Moulds, 2010). Negative self-statements (e.g., "I can't stand this anymore") are also strongly associated with negative affect (Ronan, Kendall, \& Rowe, 1994). Trainings targeted at reducing negative thoughts or replacing negative thoughts with positive ones are shown to effectively reduce the distress caused by thinking negatively (Dua \& Price, 1993).

With respect to disordered eating, Verplanken and Velsvik (2008) examined the effects of negative body image thinking, or how frequently and automatically one tends to think about his/her body in a negative manner. The authors found that thinking negatively about one's body accounted for significant variance in selfesteem and propensity for eating disturbances even after controlling for body image dissatisfaction. This suggests that it is not simply the attitude or dissatisfaction with one's body that leads to unconstructive outcomes, but the process of thinking the negative thoughts themselves that are associated with negative outcomes. Although negative body image thinking is associated with body dissatisfaction, the habitual occurrence of such thinking, or propensity to think automatically and frequently about one's body, has shown to cross-sectionally predict body dissatisfaction, eating 
disturbance propensity, low self-esteem, and restrained eating over and above the content of such thoughts (Verplanken \& Tangelder, 2011).

However, thinking about negative topics does not always lead to unconstructive outcomes and positive thinking does not always lead to constructive outcomes. The cognitive processes involved during these types of thoughts can moderate the consequences of repetitive thinking.

\section{Construal.}

As valence represents the structure of the repetitive thoughts, construal represents the process (Watkins, 2008). In a review of the literature, Watkins (2008) explains how construals can be viewed on two levels. The first level consists of concrete, low-level construals that involve thinking in simplistic, observable terms. This often includes thinking of one's sensory experience (e.g., "My clothes feel tight"). The second level consists of abstract, higher-level construals that involve thinking about one's experience in general, interpretive, and schematic terms (e.g., "I am fat").

Level of construal can lead to constructive or unconstructive consequences; repetitive thoughts that are more concrete tend to result in more constructive outcomes while thoughts that are more abstract tend to result in more unconstructive outcomes (Watkins, 2008). Reduced concreteness in repetitive thoughts has been found in several clinical populations, including those experiencing depression (Watkins \& Moulds, 2007), anxiety (Stöeber \& Borkovec, 2002), and trauma (Ehring, Frank, \& Ehlers, 2008). 
Rawal, Williams, and Park (2011) recently assessed the abstract and concrete thought processes in those with eating pathology. Overall, the authors found those instructed to focus on the self in a concrete manner (e.g., focus attention on the experience of their physical sensations, how sad or happy they are feeling, etc.) reported less need to compensate or escape their experience after being exposed to a stressor - in this case, imagining eating a large meal - compared to those instructed to focus on the self abstractly (e.g., think about the causes, meanings, and consequences of their physical sensations, how sad or happy they are feeling, etc.). Therefore, the way one thinks can affect the perceived need to avoid distressing experiences. In this sense, it is likely that more abstract construals have positive associations with experiential avoidance while concrete construals will not.

It has been shown that training individuals to think with concrete construals results in constructive outcomes (e.g., Watkins, Moberly, \& Moulds, 2005). The recent "third wave" cognitive therapies, including Acceptance and Commitment Therapy (ACT; Hayes, Luoma, Bond, Masuda, \& Lillis, 2006), Dialectical Behavior Therapy (DBT; Lynch, Chapman, Rosenthal, Kuo, \& Linehan, 2006; Linehan, 1993), and Mindfulness-Based Cognitive Therapy (MBCT; Segal, Williams, \& Teasdale, 2001), incorporate techniques to help individuals become more grounded in the present moment and think more concretely. For example, ACT uses the concept of cognitive defusion to help individuals change the way they process and relate to their thoughts instead of changing the content of the thoughts. This may include adopting an observant, non-judgmental stance to simply notice thoughts as they arise. Such a 
stance allows them to think about their sensory experiences rather than create schematic interpretations of what the experiences may mean.

\section{Repetitive thinking and avoidance.}

The reduced concreteness theory (Stöber, 1998) posits that worry is maintained through a reduction in concrete construals. Instead of thinking about the experience itself, those who worry tend to think about the consequences and interpretations of their experiences as if they are telling a story outside of themselves, sidestepping a personal connection with the experience. This manner of abstract thinking can be seen as a means of avoidance (Borkovec, Ray \& Stöber, 1998) as it inhibits one's ability to accurately analyze problems (Stöber, Tepperwien, \& Staak, 2000) or process emotionally charged topics (Borkovec \& Roemer, 1995).

Conversely, concrete thoughts are negatively related with avoidance (Cribb, Moulds, \& Carter, 2006).

Rumination, another form of abstract thinking, is also a means to avoid internal experiences. Liverant, Kamholz, Sloan, and Brown (2011) found rumination to be positively associated with emotional suppression and negatively associated with acceptance of emotional states. Rumination has also shown positive associations with experiential avoidance (Cribb, et al., 2006). In a cross sectional study, Rawal, Park, and Williams (2010) found eating disorder symptoms to significantly predict higher levels of rumination and higher levels of experiential avoidance. Given this finding, and the finding that rumination is positively associated with experiential avoidance (Cribb et al., 2006), it is possible that thinking about topics and experiences abstractly 
(e.g., ruminating) is a way for those with eating disorders to avoid uncomfortable experiences, including negative core beliefs. Therefore, Stöber's (1998) reduced concreteness theory likely spans across different forms of abstract repetitive thinking and is not limited to worry.

\section{Current Study}

The current study aims to assess the relationships between negative core beliefs, overvaluation of weight and shape, repetitive thinking, and avoidance among those with disordered eating. Figure 2 represents the proposed model.

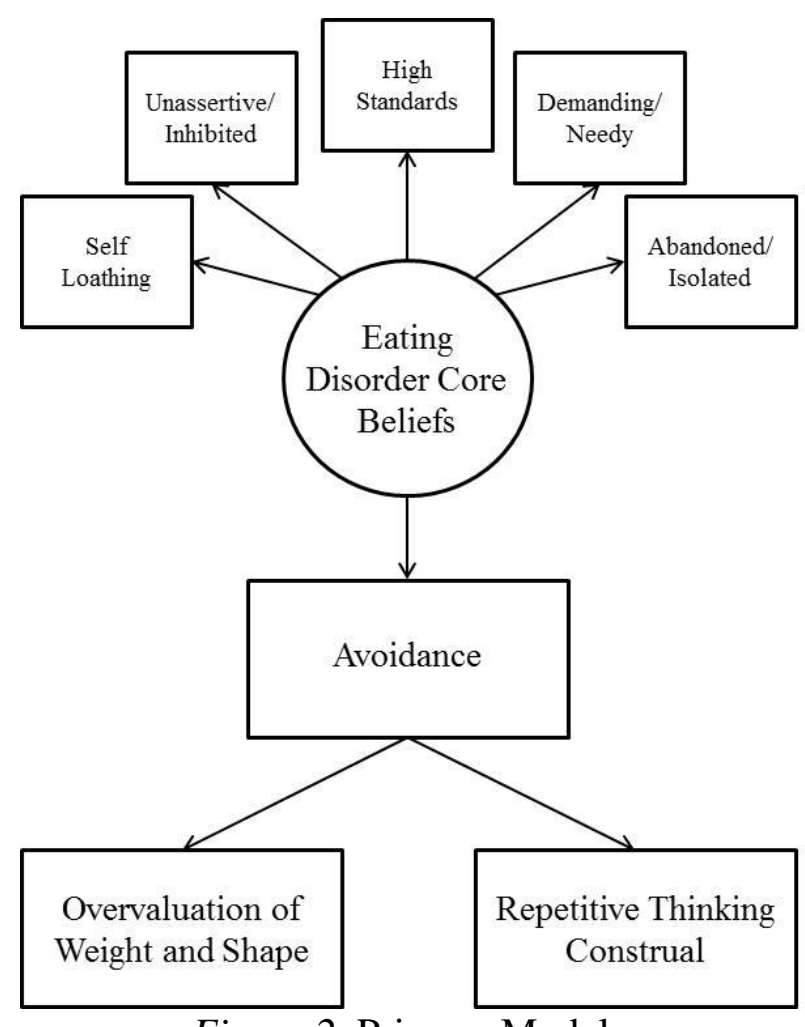

Figure 2. Primary Model

Those with eating disorders often hold negative beliefs about themselves, including beliefs that they are powerless, failures, defective, unattractive, worthless, or empty (Woolrich, Cooper, \& Turner, 2006). In order to cope with such 
uncomfortable beliefs, these individuals tend to avoid making personal connections with the meaning of the belief. In other words, they tend to avoid sitting with the notion that they are, for example, powerless. I hypothesize that high levels of negative core beliefs will be positively associated with experiential avoidance. Further, I hypothesize that overvaluation of weight and shape and repetitive thinking will serve as two mechanisms by which core beliefs can be avoided.

Polivy and Herman (1999) found those with eating disorders often attribute negative feelings to food, weight, and shape rather than to personal failures. Negative core beliefs are likely avoided by placing sole focus and blame on one's appearance rather than on beliefs that one is a failure - overvaluation of weight and shape can "mask" any negative core beliefs that an individual may have, which thereby allows them to avoid connecting with such beliefs. Therefore, it is hypothesized that avoidance will be positively associated with overvaluation of weight and shape.

The process of thinking repetitively may also serve as way to avoid core beliefs for those with eating disorders. Repetitive thinking has shown significant relationships with both experiential avoidance (Cribb, et al., 2006) and disordered eating (Rawal, Park, \& Williams 2010). Repetitive thoughts can be described according to their valence and construal (Watkins, 2008). Past research has shown that valence can lead to unconstructive consequences (e.g., depression, anxiety, disordered eating); however, it is likely that how an individual thinks (construal abstractly or concretely) is a better indicator of whether the thoughts serve an avoidant function. Therefore, it is hypothesized that abstract thoughts will be positively associated with experiential avoidance. 


\section{METHOD}

\section{Participants}

Data were collected through an online survey (surveymonkey.com), which took approximately 30 minutes to complete. Participants were not offered compensation for their participation. Because the study aims to test associations, a wide variety of eating disorder symptoms were necessary - a range of participants with higher levels of disordered eating (e.g., clinical samples) to lower levels of disordered eating (e.g., community samples) were sought. This range was recruited through both online and offline methods, and both clinical and community samples were recruited using both methods in attempt to neutralize potential differences resulting from sampling methodology.

Clinical samples were recruited from ED related websites (Gürze Books and Something Fishy), and three counseling practices in the US West and US Midwest. Community samples were recruited from several classrooms and listervs of a large US Southern university and through social networking sites.

A total of 345 participants enrolled in the survey. However, 16 were removed from analyses after incorrectly or incompletely answering at least two of the three attention checks. Further, participants who did not complete the repetitive thinking task were removed from the sample. This left a total of 244 participants. $84.8 \%$ selfidentified as female, $14.8 \%$ identified as male, and $0.4 \%$ identified as transgendered male. Independent samples t-tests were used to compare genders (females v. non 
females) on the variables in the model. Females expressed higher levels of eating disorder symptoms $(M=22.62, S E=1.04)$ than non-females $(M=13.54, S E=1.51)$. This difference was significant $t(75.23)=-4.96, p<.001$ with a medium effect size $(r$ $=.34)$. Females also expressed higher levels of experiential avoidance $(M=21.48$, $S E=0.64)$ than non-females $(M=17.41, S E=1.30)$, and this difference was significant $t(242)=-2.52, p=.012$, though the effect size for this difference was small $(r=.23)$. Females and non-females did not significantly differ with regard to negative core beliefs, hypomania, overvaluation of weight and shape, repetitive thinking construal, or repetitive thinking valence scores. Overall, females and nonfemales did not significantly differ on the majority of variables and were, therefore, combined into a single sample.

This final sample included 244 participants with an average age of 30.07 years $(S D=13.82)$. The sample was largely White/European American $(88.1 \%)$, followed by Black/African American (5.7\%), Mixed Race/Ethnicity (2.5\%), Hispanic or Latino/a (1.6\%), Asian or Pacific Islander (1.2\%), and Other (0.8\%). The majority of the sample considered the US South (63.1\%) to be their geographic home, while $28.7 \%$ originated from the US Midwest, $2.9 \%$ from the US West, $2.5 \%$ from the US Northeast, and $0.4 \%$ from the US Pacific; $2.0 \%$ identified an international location. Regarding recruitment methods, $80.3 \%$ learned of the survey through the proposed community-based recruitment methods (i.e., social networking, university classrooms, university listservs), 12.7\% through clinical-based (i.e., counseling centers and ED-related websites), and 6.6\% reported learning about the survey from another source (e.g., through a family member or a friend). 


\section{Measures}

\section{Demographics}

In order to collect an accurate description of the sample, participants will be asked to provide information related to their race/ethnicity, age, sex, geographic location, and how they heard about the study (e.g., Facebook, clinic, classroom, etc.).

Experiential Avoidance. The Acceptance and Action Questionnaire Second Edition (AAQ-II; Bond et al., 20110 was used to measure experiential avoidance. The AAQ-II is a self-report questionnaire consisting of 7 items rated on a Likert-type scale ranging from 1 (never true) to 7 (always true). A total score is created by summing the items, with higher scores indicating greater experiential avoidance. Example items include "My painful memories prevent me from having a fulfilling life" and "Emotions cause problems in my life." This revised questionnaire demonstrates adequate convergent validity with the previous AAQ (Hayes, et al., $2004 ; r=.82$ ) yet presents superior reliability estimates to the earlier version; internal consistency coefficients of the AAQ-II range from .78 to .88. Internal consistency of the scale with the current sample is reported at an $\boldsymbol{\alpha}$ level of .93.

Core Beliefs. The Eating Disorder Core Belief Questionnaire (ED-CBQ; Fairchild \& Cooper, 2010) was selected to assess the severity of core beliefs. The questionnaire consists of 40 adjectives representing negative self-beliefs common among those with eating disorders. Participants are instructed to rate how true each adjective describes them on a Likert-type scale ranging from 1 (feels very much untrue) to 7 (feels very much true). Mean scores of specific items can be calculated to create five subscales: Self-Loathing (e.g., "Inhuman", "Repulsive"), 
Unassertive/Inhibited (e.g., "Meek", "Submissive") High Standards for Self (e.g., "Conscientious", "Meticulous"), Demanding/Needing Help and Support (e.g., "Needy", "Immature"), and Abandoned/Isolated (e.g., "Betrayed", "Misunderstood"). The subscales demonstrate adequate validity, correlating with measures of eating disorder symptoms $(r=.26-.38)$. Reliability of the measure is strong; past internal consistencies of the subscales range from .76 to .96 (Fairchild \& Cooper, 2010). For the current sample, the internal consistency of the combined ED-CBQ subscales is strong $(=.95)$.

Disordered Eating. Combining items from the Eating Disorder Examination (EDE; Fairburn \& Cooper, 1993) and the Structured Clinical Interview for DSM (SCID; Spitzer, Williams, Gibbon, \& First, 1990), the Eating Disorder Diagnostic Scale (EDDS; Stice, Telch, \& Rizvi, 2000) is a brief, self-report measure to assess eating disorder symptomatology and diagnoses. The instrument consists of 22 items capable of concurrently predicting eating disorder diagnoses (e.g., "Over the past 3 months have you had a definite fear that you might gain weight or become fat?"). Items are then scored either by hand or using a computer algorithm (Stice, Fisher, \& Martinez, 2004) to create a continuous eating disorder symptom composite, making the measure applicable for non-clinical populations as well as clinical individuals, as well as full and subthreshold DSM-IV-TR diagnoses. The EDDS has demonstrated good reliability - internal consistency coefficients ranging from .86 to .91 (Stice, Fisher, \& Martinez, 2004; Stice, Telch, \& Rizvi, 2000). The EDDS also shows adequate convergent validity, significantly correlating with an existing measure of eating disorder symptomatology ( $r=.82$; Stice, Fisher, \& Martinez, 2004). 
In the current sample, 165 participants $(67.6 \%)$ did not meet requirements for any eating disorder diagnosis, whether full or subthreshold. Three individuals (1.2\%) met criteria for AN, $24(9.8 \%)$ for BN, and 18 (7.4\%) for BED. Further, 8 individuals (3.3\%) met criteria for subthreshold AN, $22(9.0 \%)$ for subthreshold $\mathrm{BN}$, and 4 (1.6\%) for subthreshold BED, meaning they met the majority of criteria for a full eating disorder diagnosis but not all. The internal consistency for the current sample is reported at $\boldsymbol{\alpha}=.80$, which is lower than found in previous studies (e.g., Stice et al., 2004) but within an acceptable range.

Overvaluation of Weight and Shape. Weight and shape overvaluation was measured using the Beliefs About Appearance Scale (BAAS; Spangler \& Stice, 2001). This 20-item instrument is aimed at assessing how individuals believe their appearance will impact their lives; example items include, "My value as a person depends on how I look" and "The opportunities that are available to me depend on how I look." Agreement with each item is rated on a 5-point Likert scale ranging from 0 (not at all) to 4 (extremely). Items are summed to create a total score, with higher scores indicating higher levels of overvaluation of weight and shape. The BAAS has shown good internal consistency in previous studies, with $\boldsymbol{\alpha}$ levels ranging from .94 to .96 (Spangler \& Stice, 2001), and showed strong alpha levels with the current sample $(=.98)$.

Repetitive Thinking. Repetitive thoughts were measured following the procedures of Segerestrom et al. (2003). Participants were prompted with the following text asking them to provide thoughts on a specific topic related to food, weight, exercise, or body shape (RT-Specific; adapted from Segerstrom et al., 2003): 
Take the next few minutes to think of something that has been on your mind lately, regarding food, your body weight, body shape, or exercise. Think of something that you have thought about frequently or for extended periods of time. In the following space, please provide a detailed description of your thoughts. In addition to describing what you have been thinking about, please also include how you have been thinking about the topic, for example, where and when you have the thoughts and the kind of thoughts they are. Please provide specific examples of thoughts you often have, including the words and phrases you think to yourself, whenever possible.

Although the last sentence of the above instructions was not included in Segerstrom et al (2003), it was included for the current study with the intent that it may encourage participants to provide longer, more specific comments, thereby allowing for a more valid content analysis. Two independent raters coded each participant's response in its entirety for its valence and construal. Valence was rated on a Likert scale ranging from 1 (very positive) to 5 (very negative). Thoughts coded as positively valenced were those that consisted of themes relating to achievement, success, or growth; personal pride and praise; interpersonal accord, harmony, or love; recreation; and positive events (e.g., weddings, reunions; Segerstrom et al., 2003). Conversely, negatively valenced thoughts consisted of themes related to failure, disappointment, or difficulty making progress; criticism; conflict or loneliness; and negative events (e.g., loss, health crises, separations).

Construal was rated on a Likert scale ranging from 1 (very concrete) to 5 (very abstract). Concrete thoughts consisted of those describing observable experiences. For example, this may have included physical sensations (e.g., hot, cold, tingle, tight) or explicit behaviors (e.g., racing thoughts, restricting food, smiling, laughing). Conversely, abstract thoughts included those that describe the causes, consequences, 
and meanings of their experiences. This may have included describing emotional constructs (e.g., hopeful, friendly, depressed), making interpretations (e.g., I am fat; I felt lazy; He was mean), or processing the effects of experiences (e.g., I'm going to fail; They will never forgive me; Everything will be better soon). Agreement between raters was calculated using correlation. $\boldsymbol{\alpha}$ levels greater than or equal to .70 are considered acceptable (Lombard, Snyder-Duch, \& Bracken, 2002). The current study found $\quad=.92$ for Valence and $\quad=.83$ for Construal.

Hypomania (Hypomanic Personality Scale-20; HPS-20; Meads \& Bentall, 2008). The HPS-20 was used to test the alternative model and is the construct that most appropriately opposes experiential avoidance. This measure captures such constructs as sociability, increased energy levels, and high ambition. It includes 20 items, reduced from the original, 48-item HPS (Eckblad \& Chapman, 1986). Each item is rated on a dichotomous True - False scale. Example items include, "I very frequently get into moods where I wish I could be everywhere and do everything at once" and "I frequently find that my thoughts are racing." The measure is highly correlated with the 48-item HPS $(r=.94)$, showing strong validity. Its internal consistency has been reported at $\alpha=.80$ in previous studies (Meads \& Bentall, 2008) and at .80 in the current study.

\section{Procedures}

Despite various recruitment methods, participants all completed the same questionnaire with each test presented in the same order, starting with demographic information and followed by the AAQ-II, EDDS, ED-CBQ, BAAS RT-Specific, and HPS-20. The survey was completed through the website SurveyMonkey. 


\section{Analyses}

The first step of the analyses was to assess demographics of the sample. This includes determining means, standard deviations, and/or percentages based on race/ethnicity, age, sex, and geographic location, eating disorder symptomatology, eating disorder core beliefs, repetitive thinking, overvaluation of weight and shape, and experiential avoidance to describe the sample. The online and offline subsamples were then compared along these variables to demonstrate that the samples are relatively comparable and capable of being analyzed as a single group.

Second, a correlation matrix will be constructed to examine the relationships between eating disorder core beliefs, repetitive thinking, overvaluation of weight and shape, and experiential avoidance - core beliefs will be split into the five subscales of the ED-CBQ and repetitive thinking will be split into valence and construal dimensions. Only those subscales of the ED-CBQ that are significantly correlated with the EDDS composite scale will be included in the analyses. This will ensure that the current study is not simply measuring negative core-beliefs in general, but only those beliefs directly related to eating disorders. Due to the negative nature of the constructs, it is hypothesized that all variables will be significantly and positively correlated with one another.

Third, a structural equation model (Figure 2) will be constructed using the maximum likelihood method in order to assess model fit with AMOS 21. The model's goodness of fit will be tested using a variety of fit statistics. A nonsignificant $\chi^{2}$ value indicates good model fit. However, as the $\chi^{2}$ statistic is known to be influenced by sample size, the root mean squared of the residuals (RMSEA; Steiger \& 
Lind, 1980), Tucker-Lewis Index (TLI; Tucker \& Lewis, 1973), and Comparative Fit Index (CFI; Bentler, 1990) will also be incorporated into the interpretation of overall model fit. According to $\mathrm{Hu}$ and Bentler (1999), an RMSEA value of .00 indicates a perfect model fit, a value less than or equal to .05 indicates good model fit, and a value less than or equal to .08 is seen as acceptable. Further, TLI and CFI values of greater than or equal to .95 indicate a good model fit, while values greater than or equal to .90 are acceptable (Hu \& Bentler, 1999).

An alternative model will be tested to assess the appropriateness of the proposed model, measuring the relationship between core beliefs, repetitive thinking, overvaluation of weight and shape, and hypomanic symptoms (Figure 3) so that repetitive thinking and overvaluation of weight and shape influence experiential avoidance, and experiential avoidance influences negative core beliefs. The original model proposes that

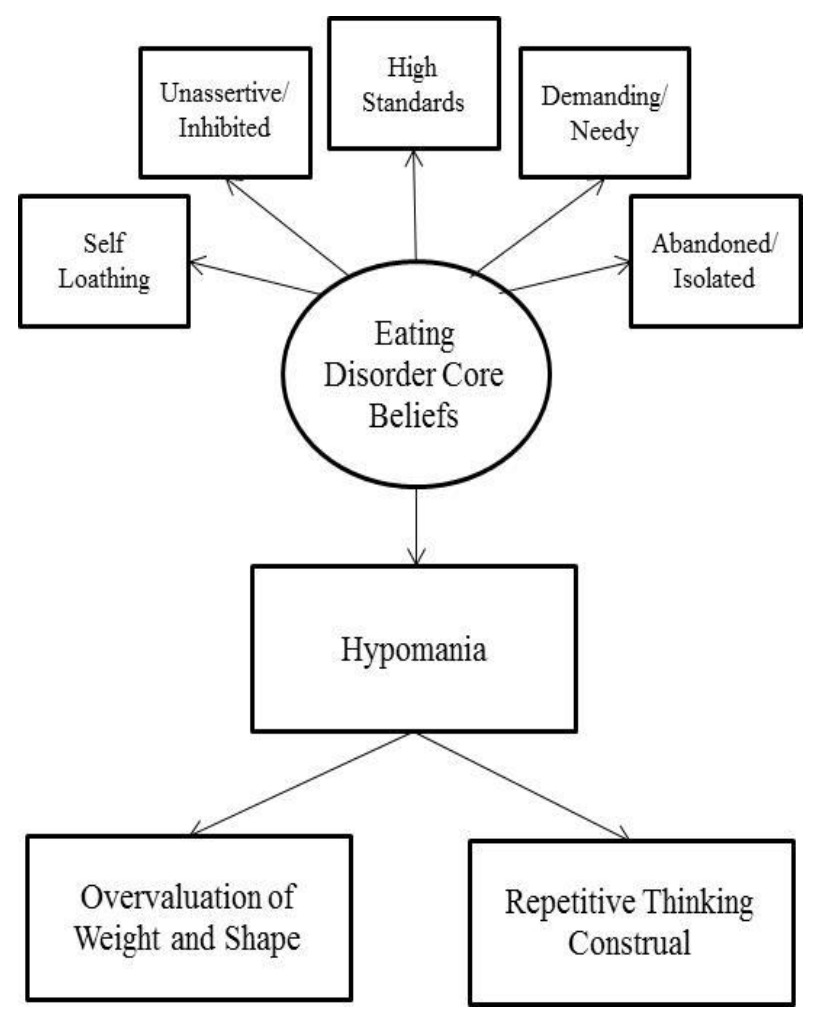

Figure 3. Alternative Model 
overvaluation of weight and shape and repetitive thinking paradoxically allow the thinker to avoid their negative core beliefs, even though the focus of thoughts seem to be on such negative qualities. The alternative model is expected to provide further support for the hypothesis by determining if the model showing that overvaluation and repetitive thinking are means of avoidance rather than means of hypomania (i.e., the opposite of avoidance). The model fit of the alternative model is hypothesized to be worse than that of the original model because the act of fixating on the content of negative beliefs through overvaluation and repetitive thinking is theorized to paradoxically be a way to avoid the thinker's core beliefs.

Two tests will be used to compare the primary model with the alternative model. First, the CFI of the alternative model was subtracted from the CFI of the primary model in order to calculate $\triangle \mathrm{CFI}$. When the $\triangle \mathrm{CFI}$ between the two models is greater than .002 , the model with the higher CFI is said to be a better fit to the data (Meade, Johnson, \& Braddy, 2008). Second, the AIC values of both models will be compared to determine which was a better fit to the data, with the model with the lower AIC value as the better fit to the data (Akaike, 1974). The difference between the two values ( $\triangle$ AIC) can be interpreted as follows: (a) $\triangle \mathrm{AIC}$ of $0-2$ indicates substantial support for the competitiveness between the two models, (b) $\triangle \mathrm{AIC}$ of 4-7 indicates weak support for the competiveness between the two models, and (c) $\triangle \mathrm{AIC}$ greater than 10 indicates essentially no equivalency between the two models (Burnham \& Anderson, 2002). 


\section{RESULTS}

Independent samples t-tests revealed that those participants who were recruited offline expressed higher levels of hypomania $(M=8.33, S E=0.41)$ than those recruited online $(M=6.27, S E=0.31)$. This difference was significant, $t(222)=-3.77, p<.001$, though the effect size was small $(r=.25)$. Further independent samples t-tests revealed no significant differences between those participants recruited online and those recruited offline with regard to eating disorder symptoms (online: $M=22.57, S E=1.32$; offline: $M$ $=20.36, S E=1.38 ; t(225)=1.12, p=.26)$, negative core beliefs (online: $M=2.58, S E=$ 0.09; offline: $M=2.57, S E=0.11 ; t(225)=1.02, p=.92)$, experiential avoidance (online: $M=21.33, S E=0.84$; offline: $M=20.38, S E=0.81 ; t(219)=0.82, p=.41$ ), beliefs about appearance (online: $M=30.90, S E=1.92$; offline: $M=30.04, S E=2.18$; $t(225)=0.29, p=.77$ ), repetitive thought construal (online: $M=3.33, S E=0.08$; offline: $M=3.51, S E=0.10 ; t(225)=-1.33, p=.18)$, or repetitive thought valence (online: $M=$ 3.46, $S E=0.07$; offline: $M=3.27, S E=0.09 ; t(225)=1.71, p=.09)$. Therefore, the current study included both the online and offline groups in a single sample. Correlations between the variables for this overall sample were then calculated. First, the five EDCBQ subscales were correlated with the total EDDS score to determine which core belief constructs were significantly associated with eating disorder symptoms. Self-Loathing ( $r$ $=.56, p<.001)$, Unassertive/Inhibited $(r=.39, p<.001)$, Demanding/Needing Help and Support $(r=.55, p<.001)$, and Abandoned/Isolated $(r=.56, p<.001)$ were all 
significantly and positively correlated with eating disorder symptoms. The High Standards for Self subscale was not significantly correlated with eating disorder symptoms $(r=-.06, p=.39)$ and was excluded from further analyses, including the Total ED-CBQ construct.

Correlations between all primary variables (beliefs about appearance, experiential avoidance, negative core beliefs, eating disorder symptoms, valence of repetitive thoughts, and construal of repetitive thoughts) were assessed, with all variables significantly correlated with each other at the $p<.001$ level and in the hypothesized direction. These Pearson correlations, means, and standard deviations for the full EDCBQ scale and all remaining primary variables can be found in Table 1 .

Table 1

Correlations, Means, and Standard Deviations of Primary Variables in Model

\begin{tabular}{lccccccc}
\hline \multicolumn{1}{c}{ Variable } & 1 & 2 & 3 & 4 & 5 & 6 & 7 \\
\hline 1. Negative Core Beliefs & - & & & & & & \\
2. Avoidance & $.67^{* *}$ & - & & & & & \\
3. Overvaluation & $.66^{* *}$ & $.57^{* *}$ & - & & & & \\
4. ED Symptoms & $.62^{* *}$ & $.62^{* *}$ & $.74^{* *}$ & - & & & \\
5. RT Valence & $.50^{* *}$ & $.53^{* *}$ & $.50^{* *}$ & $.52^{* *}$ & - & & \\
6. RT Construal & $.35^{* *}$ & $.27^{* *}$ & $.20^{*}$ & $.26^{* *}$ & $.43^{* *}$ & - & \\
7. Hypomania & $.37^{* *}$ & $.34^{* *}$ & $.40^{* *}$ & $.41^{* *}$ & $.23^{* *}$ & $.24^{* *}$ & - \\
$M$ & 2.60 & 20.86 & 29.98 & 21.24 & 3.37 & 3.38 & 6.98 \\
$S D$ & 1.06 & 9.14 & 21.78 & 14.57 & 0.85 & 0.96 & 4.13 \\
\hline
\end{tabular}

Note. $\mathrm{ED}=$ eating disorder; $\mathrm{RT}=$ repetitive thinking ${ }^{* *} p<.001,{ }^{*} p=.002$ 
The measurement model was then tested to, first, assess the fit of the ED-CBQ latent construct to the data using a Confirmatory Factor Analysis (CFA). As previously mentioned, only the Self-Loathing, Unassertive/Inhibited, Demanding/Needing Help and Support, and Abandoned/Isolated subscales were included in the analyses due to their significant correlation with eating disorder symptoms (High Standards for Self was not significantly correlated with eating disorder symptoms and was removed from the construct). The measurement model can be found in Figure 4.

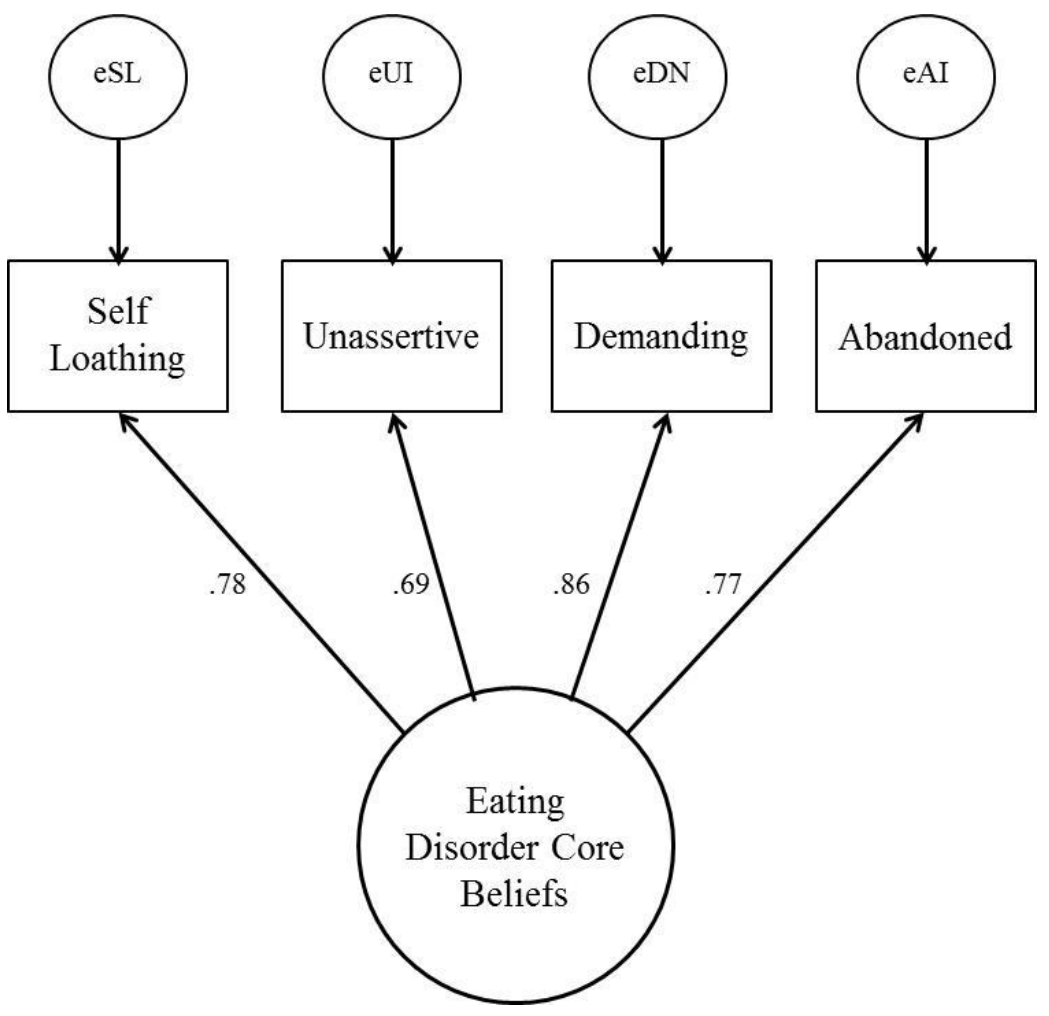

Figure 4. Eating Disorder Core Beliefs CFA

The proposed one factor structure was found to be a good fit to the data. The model achieved a $\chi^{2}(2, N=244)=1.40, p=.50$, indicating good model fit. Further, CFI $=1.00, \mathrm{TLI}=1.00$, and RMSEA $=.000$. 
The current study's primary model was tested for model fit, indicating poor model fit, $\chi^{2}(14, N=244)=88.83, p<.000, \mathrm{CFI}=.903, \mathrm{TLI}=.855$, and RMESA $=.148$. The alternative model did not fit well to the data either, $\chi^{2}(14, N=244)=160.17, p<.001$, $\mathrm{CFI}=.782, \mathrm{TLI}=.563$, and RMSEA $=.207$.

Comparisons of the primary and the alternative model indicated that the primary model fit to the data significantly better, $\triangle \mathrm{CFI}=.121$. With regard to AIC, the primary model achieved an AIC value of 130.83 while the alternative model achieved a value of 202.17; therefore, $\triangle \mathrm{AIC}=71.74$, indicating the models are not equivalent or competitive and the primary model was a better fit to the data than the alternative model. Overall, the two models are significantly different and the primary model was a better fit to the data than the alternative model.

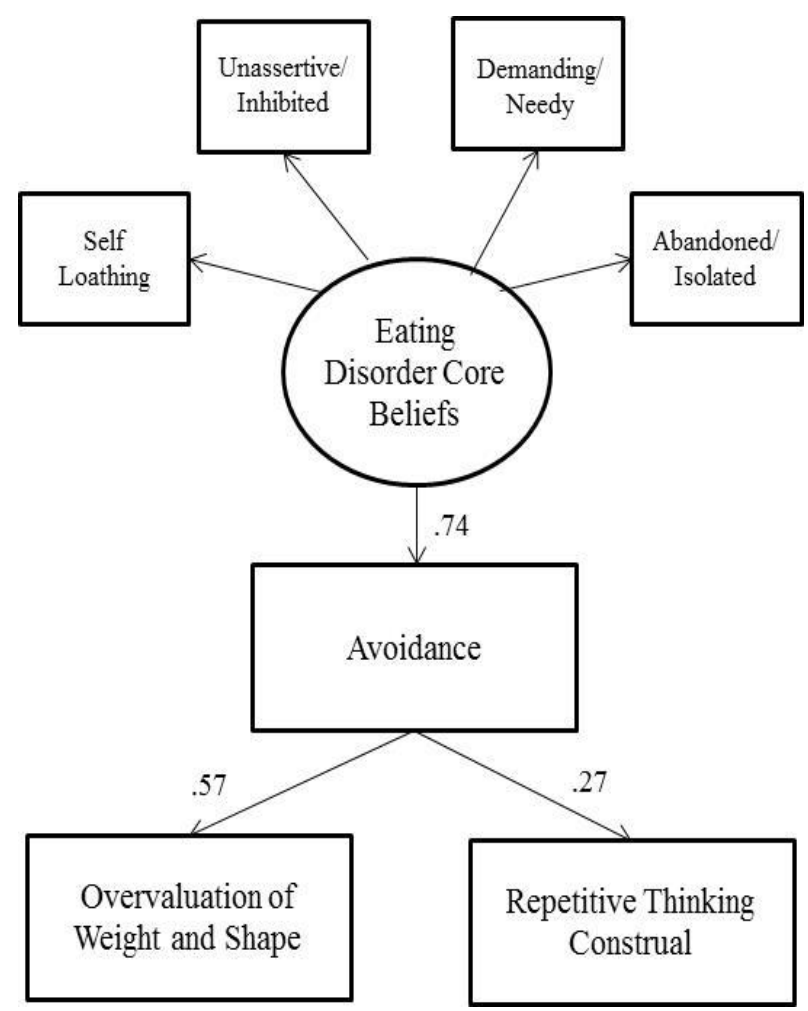

Figure 5. Standardized Regression Weights of Primary Model 
The primary model also revealed significant $(\mathrm{p}=.001)$ standardized regression weights for each path in the model (Figure 5). These coefficients ranged from .27 to .74 , indicating small to large effects (Klein, 2011).

The alternative model also revealed significant standardized regression weights $(\mathrm{p}$ $=.001$; Figure 6 ) with coefficients ranging from .24 to .43 , indicating the variables in the model have small to medium effects.

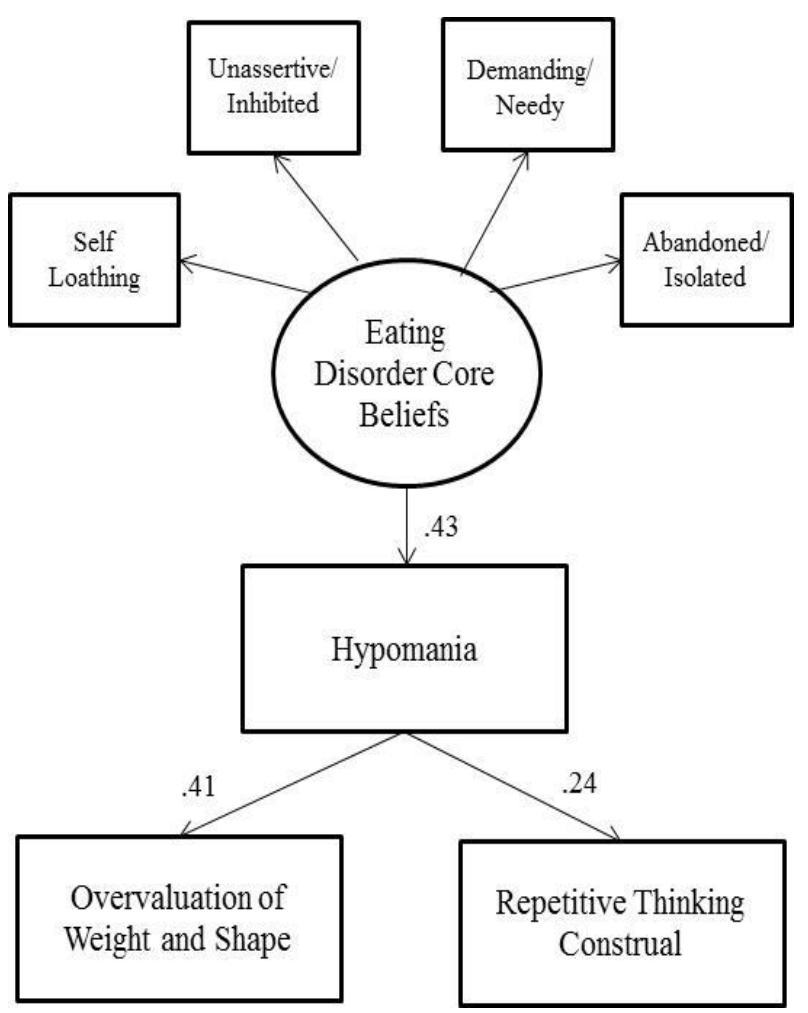

Figure 6. Standardized Regression Weights of Alternative Model

Overall, the primary model accounts for more variance than the alternative model, and this appears to be due to the differences in the associations of experiential avoidance and hypomania with the other variables in the model. In the primary model, eating 
disorder core beliefs accounted for $55 \%$ of the variance in experiential avoidance, indicating a large effect size. Conversely, eating disorder core beliefs in the alternative model only accounted for $18 \%$ of the variance in hypomania, indicating a medium effect size. In the primary model, avoidance accounted for $32 \%$ of the variance in overvaluation of weight and shape and $7 \%$ of the variance in repetitive thinking construal. In the alternative model, hypomania accounted for $17 \%$ of the variance in overvaluation of weight and shape and $6 \%$ of the variance in repetitive thinking construal. 


\section{DISCUSSION}

The current study aimed to assess the relationships between negative core beliefs, overvaluation of weight and shape, repetitive thinking, and experiential avoidance among those with disordered eating. It was hypothesized that these variables would have a significant, positive relationship with one another. Results supported this hypothesis in that all variables have positive and significant correlations with all other variables in the study. For example, higher levels of negative core beliefs were related to higher levels of overvaluation of weight and shape, higher levels of abstract repetitive thinking, and higher levels of experiential avoidance. This is congruent with the current study's first hypothesis as well as previous literature showing positive relationships between the aforementioned variables (e.g., Cooper, Wells, \& Todd, 2004; Cowdrey \& Park, 2012; Rawal, Park, \& Williams, 2010). Further, the strength of associations of the paths in the primary model were positive and significant, indicating the variables significantly relate to all other variables. The association between eating disorder core beliefs and experiential avoidance accounted for the most variance in the primary model, while the association between experiential avoidance and repetitive thinking construal accounted for the least.

It was also postulated that overvaluation of weight and shape and abstract repetitive thinking are two mechanisms by which negative core beliefs are avoided for those with high levels of disordered eating. More specifically, it was hypothesized that overvaluation of weight and shape and abstract repetitive thinking are related to negative 
core beliefs through experiential avoidance (i.e., the primary model). Further, it was hypothesized that the role of experiential avoidance would play a stronger role in this overall relationship than would hypomania - that overvaluation and abstract repetitive thinking would be more related to negative core beliefs through experiential avoidance than through hypomania. Neither the primary nor the alternative model were good fits to the data; however, the primary model was a better fit to the data and revealed stronger associations between variables than the alternative model, suggesting that avoidance, rather than hypomania, is a better mechanism involved in the relationship between negative core beliefs, overvaluation of weight and shape, and abstract repetitive thinking.

For the primary model, the association between eating disorder core beliefs and experiential avoidance and the association between experiential avoidance and overvaluation of weight and shape were both significant and strong - increases in negative core beliefs were significantly and largely associated with increases in experiential avoidance while increases in experiential avoidance were significantly and moderately associated with increases in overvaluation of weight and shape. Although increases in experiential avoidance were significantly related to increases in abstract repetitive thinking, this effect was small. Similarly, the current study also revealed significant but weak associations between repetitive thinking and negative core beliefs, overvaluation of weight and shape, and eating disorder symptoms.

Based on the results, overvaluation of weight and shape is strongly connected to both experiential avoidance and negative core beliefs, supporting the notion that overvaluation is capable of serving as an intermediate belief (i.e., rules, attitudes, and assumptions about weight and shape) that allows the individual to avoid tolerating or 
sitting with any negative core beliefs they hold about him-/herself as a person. Polivy and Herman (1999) identify this as the masking of distress hypothesis, in which it is less distressing for individuals to place undue attentional focus on food, weight, and shape than on negative thoughts about themselves. Future studies should investigate whether avoidance is capable of fully or partially mediating the relationship between negative core beliefs and overvaluation of weight and shape. An experimental design is also recommended in order to more accurately capture the process, due to it's ability to assess causal relationships (i.e., triggering negative core beliefs to assess if the beliefs initiate the onset of avoidance through repetitive thinking and/or overvaluation of weight and shape) as well as constraining confounding variables by randomly assigning participants into test or control condition. Overall, an experimental design would better assess for if a direct, casual relationship exists between the variables.

The results also show abstract repetitive thoughts are related to negative core beliefs through experiential avoidance, suggesting that thinking in more generalized, interpretive, and vague terms could be a way to avoid tolerating deeply held cognitions about oneself. If less abstract (i.e., more concrete) thinking styles are associated with less experiential avoidance, it seems reasonable to suggest that promoting more concrete repetitive thought may be a way to reduce experiential avoidance in those with disordered eating. Though no studies have looked at this suggestion specifically, some have began to investigate similar relationships. For example, Mantzios and Wilson (2014) found that the participants prompted to journal concrete thoughts about the meal they ate experienced more mindfulness and self-compassion and less negative automatic thoughts and cognitive avoidance than those participants prompted to journal abstractly. It is 
unknown if having participants focus their journaling specifically on body weight and shape would produce similar results.

Despite the strength of associations between variables, the proposed primary model was not a good fit to the data. It is possible that this finding is, in part, due to the measurement and nature of the repetitive thinking construct, given it's significant but weak associations with the remaining constructs assessed by this study. More specifically, the methods used for measuring repetitive thoughts may not have been able to fully capture the construct. Participants were asked to retrospectively recall the content of their repetitive thoughts related to food, weight, body image, body shape, and exercise, and to write these thoughts on the survey. The qualitative text was then coded based on the language used by the participant. This method emphasizes the exact words the participant writes, which are likely to differ from the words used when the participant engages in repetitive though in their daily, present life. A longitudinal design that allows participants to record their thoughts as they occur could help to increase the reliability and validity of the way this construct is measured and represented, respectively, in the study. By using the exact language a person thinks with, researchers can more accurately measure the valence and construal of such repetitive thoughts, likely providing more accurate and realistic findings of how repetitive thinking relates to experiential avoidance and disordered eating. It is recommended that future studies induce negative core beliefs in their participants and record the exact content of their repetitive thoughts over time. This will allow for a testing of causal relationships between the variables (i.e., do negative core beliefs cause experiential avoidance through repetitive thinking and/or overvaluation of weight and shape) as well as how these variables interact over time. 
It is also possible that the model fit was not better due to omission of a moderating variable. Watkins (2008) suggests that, in addition to the thoughts' valence and construal, context can moderate whether that particular way of thinking leads to constructive or unconstructive outcomes. However, due to the paucity of literature on the subject, it is difficult to narrow which contextual factors could play a significant moderating role. For this reason, as well as difficulties with measuring certain contextual factors, the author of the current study chose to omit a contextual moderating variable from the analyses and instead focus on assessing the simple, direct relationships between the variables instead.

Future research should use the current study as a foundation to explore the effects of moderating contextual variables on the primary model, some of which have been suggested by past findings. For example, Watkins (2008) outlines how past literature has shown depressed mood (e.g., Lyubomirsky, Kasri, Chang, \& Chang, 2006), trait anxiety (e.g., Kashdan \& Roberts, 2007), self-efficacy (e.g., Dijkstra \& Brosschot, 2003), and stress (e.g., Mezo \& Baker, 2012) have all led to or exacerbated negative outcomes of repetitive thinking. Though the field has yet to assess what constructs moderate the value placed on body weight and shape, similar constructs have been examined. Depressed mood has shown to increase body dissatisfaction (Haedt-Matt, Zalta, Forbush, \& Keel, 2012) while both depression and anxiety increases the tendency to internalize the thin-ideal found in media messages (Pokrajac-Bulian, Ambrosi-Randic, \& Kukic, 2008).

Several studies have also revealed that individuals with low self-esteem (Chapman \& Mullis, 1999), high anxiety (Vassilopoulos, 2008), and high psychological distress (Roberts, Czajkowska, Radiotis, \& Körner, 2013) are more likely to use avoidant 
coping strategies than individuals without low self-esteem or high distress. Tobin and Griffing (1995) found the avoidant coping strategies used by those with bulimia nervosa are more attributable to the associated depressive symptoms than to the eating disorder itself. This implies that additional factors, such as depression, may actually account for additional variance in the relationships between the variables in the current study's primary model and improve model fit. It is recommended that future studies explore possible moderators that could contextually impact the nature of the proposed primary model.

Finally, the current study may be affected by its cross-sectional design and use of self-report measures, which impact causal interpretations and mono-method bias, respectively. To truly detect whether abstract repetitive thinking and overvaluation of weight and shape lead to avoidance of negative core beliefs, future studies should focus on potential moderating variables, measures with stronger construct validity, an experimental design, and multiple methods of gathering data.

Despite the aforementioned limitations, this study provides several relevant findings. First, it is the only study the author is aware of in which the relationships between eating disorder symptoms, negative core beliefs, experiential avoidance, repetitive thinking, and overvaluation of weight and shape were assessed. Second, there is a more deliberate attempt to parcel out just how these variables are connected through structural equation modeling. SEM latent variables (i.e., eating disorder core beliefs) help to reduce measurement error, which cannot be accounted for when only observed variables and regression analysis are used - regression erroneously assumes that no measurement error exists. SEM is also superior to regression in that it models 
disturbance terms, which account for the variance left unexplained by the variables in the model. Third, it is one of only a few studies on eating disorders to include genders beyond those that self-identify as female. The National Institute of Mental Health (2008) found approximately one million males experience eating disorder symptoms, which some believe to be an underrepresentation (e.g., Strother, Lemberg, Stanford, \& Turberville, 2012).

The current sample poses further strengths by including data from both online and offline samples. This method helped to increase the potential sample pool and participants reached. Further, data from both community and clinical samples were included and it was found that, overall, the two populations were similar enough to be combined into a single sample. The majority of literature on disordered eating uses either a clinical or a community sample; thus that both samples can be integrated in the same analyses poses a strength for the study's external validity as the current results could be generalized to a larger population. In order to more appropriately capture how disordered eating presents generally, it is essential to continue expanding our sample populations beyond self-identified females and clinical samples.

Overall, the current study presents with significant strengths as well as recommendations for future studies. It was found that negative core beliefs, experiential avoidance, eating disorder symptoms, abstract repetitive thought, and overvaluation of weight and shape has significant and positive relationships with one another. The current study provides a significant contribution to the field by revealing the how the variables in the study relate to each other. The field should continue exploring these relationships, how they are impacted and associated as a whole - in the hopes of using the findings to 
better determine how avoidance presents in those with disordered eating, leading to more effective ways of addressing these aspects through prevention and intervention. 


\section{REFERENCES}

Alado, A., \& Nolen-Hoeksema, S. (2010). Specificity of cognitive emotion regulation strategies: A transdiagnostic examination. Behaviour Research and Therapy, 48, 974-983.

Alado, A., Nolen-Hoeksema, S., \& Schweizer, S. (2010). Emotion-regulation strategies across psychopathology: A meta-analytic review. Clinical Psychology Review, 30, 217-237.

Allaz, A., Bernstein, M., Rouget, P., Archinard, M., \& Morabia, A. (1998). Body weight preoccupation in middle-age and ageing women: A general population survey. International Journal of Eating Disorders, 23, 287-294.

Allen, A. B., \& Leary, M. R. (2010). Self-compassion, stress, and coping. Social and Personality Psychology Compass, 4, 107-118.

American Psychiatric Association. (2000). Diagnostic and statistical manual of mental disorders (4th ed., text rev.). Washington, DC: Author.

Arcelus, J., Mitchell, A. J., Wales, J., \& Nielson, S. (2011). Mortality rates in patients with anorexia nervosa and other eating disorders: A meta-analysis of 36 studies. Archives of General Psychiatry, 68, 724-731.

Armitage, C. J. (2012). Evidence that self-affirmation reduces body dissatisfaction by basing self-esteem on domains other than body weight and shape. Journal of Child Psychology and Psychiatry, 53, 81-88. 
Beck, A. T. (1976). Cognitive therapy and the emotional disorders. Oxford, England: International Universities Press.

Beck, J. S. (2011). Cognitive behavior therapy: Basics and beyond ( $2^{\text {nd }}$ ed.). New York, New York: The Guilford Press.

Bentler, P. M. (1990). Comparative fit indexes in structural models. Psychological Bulletin, 107, 238-246.

Bond, F. W., Hayes, S. C., Baer, R. A., Carpenter, K. M., Guenole, N., Orcutt, H. K., . . . Zettle, R. D. (2011). Preliminary psychometric properties of the Acceptance and Action Questionnaire-II: A revised measure of psychological inflexibility and experiential avoidance. Behavior Therapy, 42, 676-688.

Borkovec, T. D., Ray, W. J., \& Stöber, J. (1998). Worry: A cognitive phenomenon intimately linked to affective, physiological, and interpersonal behavioral processes. Cognitive Therapy and Research, 22, 561-576.

Borkovec, T. D., Robinson, E., Pruzinsky, T., \& DePree, J. A. (1983). Preliminary exploration of worry: Some characteristics and processes. Behaviour Research and Therapy, 21, 9-16.

Borkovec, T. D., \& Roemer, L. (1995). Perceived functions of worry among generalized anxiety disorder subject: Distraction form more emotionally distressing topics? Journal of Behaviour Therapy and Experimental Psychiatry, 26, 25-30.

Brausch, A. M., \& Gutierrez, P. M. (2009). The role of body image and disordered eating as risk factors for depression and suicidal ideation in adolescents. Suicide and Life-Threatening Behavior, 39, 58-71`. 
Burnham, K.P. \& Anderson, D.R. (2002). Model Selection and Multimodel Inference. Springer Verlag. (second edition).

Chapman, P. L., \& Mullis, R. L. (1999). Adolescent coping strategies and self-esteem. Child Study Journal, 29, 69-77.

Chawla, N., \& Ostafin, B. (2007). Experiential avoidance as a functional dimensional approach to psychopathology: An empirical review. Journal of Clinical Psychology, 63, 871-890.

Cooper, M. J., Wells, A., \& Todd, G. (2004). A cognitive model of bulimia nervosa. British Journal of Clinical Psychology, 43, 1-16.

Cowdrey, F. A., \& Park, R. J. (2012). The role of experiential avoidance, rumination, and mindfulness in eating disorders. Eating Behaviors, 13, 100-105.

Cribb, G., Moulds, M. L., \& Carter, S. (2006). Rumination and experiential avoidance in depression. Behaviour Change, 23, 165-176.

Devlin, M. J., Goldfein, J. A., \& Dobrow, I. (2003). What is this thing called BED? Current status of binge eating disorder nosology. International Journal of Eating Disorders, 34, S2-S18.

Dijkstra, A., \& Brosschot, J. (2003). Worry about health in smoking behaviour change. Behaviour Research and Therapy, 41, 1081-1092.

Dua, J., \& Price, I. (1993). Effectiveness of training in negative thought reduction and positive through increment in reducing thought-produced distress. The Journal of Genetic Psychology, 154, 97-109.

Eckblad, M., \& Chapman, L. J. (1986). Development and validation of a scale for hypomanic personality. Journal of Abnormal Psychology, 95, 214-222. 
Ehring, T., Frank, S., \& Ehlers, A. (2008). The role of rumination and reduced concreteness in the maintenance of posttraumatic stress disorder and depression following trauma. Cognitive Therapy and Research, 32, 488-506.

Ehring, T., Zetsche, U., Weidacker, K., Wahl, K., Schönfeld, S., \& Ehlers, A. (2011). The Perseverative Thinking Questionnaire (PTQ): Validation of a content-independent measure of repetitive negative thinking. Journal of Behaviour Therapy and Experimental Psychiatry, 42, 225-232.

Fairburn, C. G. (2008). Cognitive behavior therapy and eating disorders. New York, New York: Guilford Press.

Fairburn, C. G., \& Bohn, K. (2005). Eating disorder NOS (EDNOS): An example of the troublesome "not otherwise specified" (NOS) category in DSM-IV. Behaviour Research and Therapy, 43, 691-701.

Fairburn, C. G., \& Cooper, Z. (1993). The Eating Disorder Examination (12 ${ }^{\text {th }}$ ed.). In C. G. Fairburn \& G. T. Wilson (eds.). Binge eating: Nature, assessment, and treatment (pp. 317-360). New York, NY: Guilford Press.

Fairburn, C. G., Cooper, Z., Bohn, K., O’Connor, M. E., Doll, H. A., \& Palmer, R. L. (2007). The severity and status of eating disorder NOS: Implications for DSM-V. Behaviour Research and Therapy, 45, 1705-1715.

Fairchild, H., \& Cooper, M. (2010). A multidimensional measure of core beliefs relevant to eating disorders: Preliminary development and validation. Eating Behaviors, $11,239-246$.

Fassino, S., Abbate-Daga, G., Amianto, F., Leombruni, P., Boggio, S., \& Giacomo Rovera, G. (2002). Temperament and character profile of eating disorders: A 
controlled study with temperament and character inventory. International Journal of Eating Disorders, 32, 412-425.

Fichter, M. M., Quadflieg, N., \& Hedlund, S. (2008). Long-term course of binge eating disorder and bulimia nervosa: Relevance for nosology and diagnostic criteria. International Journal of Eating Disorders, 41, 577-586.

Franko, D. L., \& Keel, P. K. (2006). Suicidality in eating disorders: Occurrence, correlates, and clinical implications. Clinical Psychology Review, 26, 769-782.

Gale, C., Holliday, J., Troop, N. A., Serpell, L., \& Treasure, J. (2006). The pros and cons of change in individuals with eating disorders: A broader perspective. International Journal of Eating Disorders, 39, 394-403.

Goldschmidt, A. B., Hibert, A., Manwaring, J. L., Wifley, D. E., Pike, K. M., Fairburn, C. G., \& Striegel-Moore, R. H. (2010). The significance of overvaluation of shape and weight in binge eating disorder. Behaviour Research and Therapy, 48, 187193.

Grilo, C. M., Masheb, R. M., \& White, M. A. (2010). Significance of overvaluation of shape/weight in binge eating disorder: Comparative study with overweight and bulimia nervosa. Obesity, 18, 499-504.

Haedt-Matt, A. A., Zalta, A. K., Forbush, K. T., \& Keel, P. K. (2012). Experimental evidence that changes in mood cause changes in body dissatisfaction among undergraduate women. Body Image, 9, 216-220.

Hayaki, J. (2009). Negative reinforcement eating expectancies, emotion dysregulation, and symptoms of bulimia nervosa. International Journal of Eating Disorders, 42, $552-556$. 
Hayes, A. F., \& Krippendorff (2007). Answering the call for a standard reliability measure for coding data. Communication Methods and Measures, 1, 77-89.

Hayes, S. C., Luoma, J. B., Bond, F. W., Masuda, A., \& Lillis, J. (2006). Acceptance and commitment therapy: Model, processes and outcomes. Behaviour Research and Therapy, 44, 1-25.

Hayes, S. C., Strosahl, K. D., Wilson, K. G., Bissett, R. T., Pistorello, J., Toarmino, D., . . . McCurry, S. M. (2004). Measuring experiential avoidance: A preliminary test of a working model. The Psychological Record, 54, 553-578.

Hayes, S. C., Wilson, K. G., Gifford, E. V., Follette, V. M., \& Strosahl, K. (1996). Experiential avoidance and behavioral disorders: A functional dimensional approach to diagnosis and treatment. Journal of Consulting and Clinical Psychology, 64, 1152-1168.

Hu, L., \& Bentler, P. M. (1999). Cutoff criteria for fit indexes in covariance structure analysis: Conventional criteria versus new alternatives. Structural Equation Modeling: A Multidisciplinary Journal, 6, 1-55.

Just, N., \& Alloy, L. B. (1997). The response styles theory of depression: Tests and an extension of the theory. Journal of Abnormal Psychology, 106, 221-229.

Kashdan, T. B., \& Roberts, J. E. (2007). Social anxiety, depressive symptoms, and postevent rumination: Affective consequences and social contextual influences. Journal of Anxiety Disorders, 21, $284-301$.

Katzman, D. K. (2005). Medical complications in adolescents with anorexia nervosa: A review of the literature. International Journal of Eating Disorders, 37, S52-S59.

Kline, R. B. (2011). Principles and practice of structural equation modeling ( $3^{\text {rd }}$ ed.). New York, NY: Guilford Press. 
Klump, K. L., Bulik, C. M., Kaye, W. H., Treasure, J., \& Tyson, E. (2009). Academy for Eating Disorders position paper: Eating disorders are serious mental illnesses. International Journal of Eating Disorders, 42, 97-103.

Koole, S. L., Smeets, K., van Kippenberg, A., \& Dijksterhuis, A. (1999). The cessation of rumination through self-affirmation. Journal of Personality and Social Psychology, 77, 111-125.

Leary, M. R., Tate, E. B., Adams, C. E., Allen, A. B., \& Hancock, J. (2007). Selfcompassion and reactions to unpleasant self-relevant events: The implications of treating oneself kindly. Journal of Personality and Social Psychology, 92, 887904.

Linehan, M. M. (1993). Cognitive behavioral treatment of borderline personality disorder. New York, NY: Guilford Press.

Lipczynska, S. (2005). Eating disorders. Journal of Mental Health, 14, 649-651.

Liverant, G. I., Kamholz, B. W., Sloan, D. M., \& Brown, T. A. (2011). Rumination in clinical depression: A type of emotional suppression? Cognitive Therapy and Research, 35, 253-265.

Lombard, M., Snyder-Duch, J., \& Bracken, C. C. (2002). Content analysis in mass communication: Assessment and reporting of intercoder reliability. Human Communication Research, 28, 587-604.

Luck, A., Waller, G., Meyer, C., Ussher, M., \& Lacey, H. (2005). The role of schema processes in the eating disorders. Cognitive Therapy and Research, 29, 717-732.

Lynch, T. R., Chapman, A. L., Rosenthal, M. Z., Kuo, J. R., \& Linehan, M. M. (2006). Mechanisms of change in dialectical behavior therapy: Theoretical and empirical observations. Journal of Clinical Psychology, 62, 459-480. 
Lyubomirsky, S., Kasri, F., Chang, O., \& Chang, I. (2006). Ruminative response styles and delay of seeking diagnosis for breast cancer symptoms.

Masheb, R. M., \& Grilo, C. M. (2008). Prognostic significance of two sub-categorization methods for the treatment of binge eating disorder: Negative affect and overvaluation predict, but do not moderate, specific outcomes. Behaviour Research and Therapy, 46, 428-437.

McEvoy, P. M., Mahoney, A. E. J., Moulds, M. L. (2010). Are worry, rumination, and post-event processing one and the same: Development of the repetitive thinking questionnaire. Journal of Anxiety Disorders, 24, 509-519.

McLaughlin, K. A., \& Nolen-Hoeksema, S. (2011). Rumination as a transdiagnostic factor in depression and anxiety. Behaviour Research and Therapy, 49, 186-193.

Meade, A. W., Johnson, E. C., \& Braddy, P. W. (2008). Power and sensitivity of alternative fit indices in tests of measurement invariance. Journal of Applied Psychology, 93, $568-592$.

Meads, D. M., \& Bentall, R. P. (2008). Rasch analysis and item reduction of the hypomanic personality scale. Personality and Individual Differences, 44, $1772-$ 1783.

Mezo, P. G., \& Baker, R. M. (2012). The moderating effects of stress and rumination on depressive symptoms in women and men. Stress and Health: Journal of the International Society for the Investigation of Stress, 28, 333-339.

Mitchell, J. E., \& Crow, S. (2006). Medical complications of anorexia nervosa and bulimia nervosa. Current Opinion in Psychiatry, 19, 438-443. 
National Institute of Mental Health. (2008). Eating disorder statistics. Retrieved from http://www.gurze.com/client/client_pages/printable_pages/eatingdisorderstats.htm 1

Nock, M. K., \& Kessler, R. C. (2006). Prevalence of and risk factors for suicide attempts versus suicide gestures: Analysis of the National Comorbidity Survey. Journal of Abnormal Psychology, 115, 616-623.

Nolen-Hoeksema, S. (1991). Responses to depression and their effects on the duration of depressive episodes. Journal of Abnormal Psychology, 100, 569-582.

Nolen-Hoeksema, S., Morrow, J., \& Fredrickson, B. L. (1993). Response styles and the duration of episodes of depressed mood. Journal of Abnormal Psychology, 102, $20-28$.

Nolen-Hoeksema, S., Stice, E., Wade, E., \& Bohon, C. (2007). Reciprocal relations between rumination and bulimic, substance abuse, and depressive symptoms in female adolescents. Journal of Abnormal Psychology, 116, 198-207.

Nolen-Hoeksema, S., Wisco, B. E., \& Lyubomirsky, S. (2008). Rethinking rumination. Perspectives on Psychological Science, 3, 400-424.

O’Mara, E. M., McNulty, J. K., \& Karney, B. R. (2011). Positively biased appraisals in everyday life: When do they benefit mental health and when do they harm it? Journal of Personality and Social Psychology, 101, 415-432.

Pokarajac-Bulian, A., Ambrosi-Randic, N., \& Kukic, M. (2008). Thin-ideal internalization and comparison process as mediators of social influence and psychological functioning in the development of disturbed eating habits in Croatian college females. Psychological Topics, 17, 221-245. 
Polivy, J., \& Herman, C. P. (1999). Distress and eating: Why do dieters overeat. International Journal of Eating Disorders, 26, 153-164.

Rawal, A., Park, R. J., \& Williams, M. G. (2010). Rumination, experiential avoidance, and dysfunctional thinking in eating disorders. Behaviour Research and Therapy, $48,851-859$.

Rawal, A., Williams, M. G., \& Park, R. J. (2011). Effects of analytical and experiential self-focus on stress-induced cognitive reactivity in eating disorder psychopathology. Behaviour Research and Therapy, 49, 635-645.

Roberts, N., Czajkowska, Z., Radiotis, G., \& Körner, A. (2013). Distress and coping strategies among patients with skin cancer. Journal of Clinical Psychology in Medical Settings, 20, 209-214.

Rome, E. S., \& Ammerman, S. (2003). Medical complications of eating disorders: An update. Journal of Adolescent Health, 33, 418-426.

Ronan, K. R., \& Kendall, P. C. (2011). Self-talk in distressed youth: States-of-mind and content specificity. Journal of Clinical Child Psychology, 26, 330-337.

Ronan, K. R., Kendall, P. C., \& Rowe, M. (1994). Negative affectivity in children: Development and validation of a self-statement questionnaire. Cognitive Therapy and Research, 18, 509-528.

Sassaroli, S., Bertelli, S., Decoppi, M., Crosina, M., Milos, G., \& Ruggiero, G. M. (2005). Worry and eating disorders: A psychopathological association. Eating Behaviors, 6, 301-307.

Schmidt, U., \& Treasure, J. (2006). Anorexia nervosa: Valued and visible. A cognitiveinterpersonal maintenance model and its implications for research and practice. British Journal of Clinical Psychology, 45, 343-366. 
Segal, Z. V., Williams, J. M. G., Teasdale, J. D. (2001). Mindfulness-based cognitive therapy for depression: A new approach to preventing relapse. New York, NY: Guilford Press.

Segerstrom, S. C., Stanton, A. L., Alden, L. E., \& Shortridge, B. E. (2003). A multidimensional structure for repetitive thought: What's on your mind, and how, and how much? Journal of Personality and Social Psychology, 85, 909-921.

Shafran, R. (2002). Eating disorders and the internet. In C. Fairburn \& K. Brownell (Eds.), Eating Disorders and Obesity (pp. 362-365). New York, NY: Guilford Press.

Slade, P. D. (1982). Towards a functional analysis of anorexia nervosa and bulimia nervosa. British Journal of Clinical Psychology, 21, 167-179.

Spangler, D. L., \& Stice, E. (2001). Validation of the Beliefs About Appearance Scale. Cognitive Therapy and Research, 25, 813-827.

Spitzer, R. L., Williams, J. B. W., Gibbon, M., \& First, M. B. (1990). User's guide for the structured clinical interview for DSM-III-R: SCID. Washington, DC: American Psychiatric Association.

Spoor, S. T. P., Bekker, M. H. J., Van Strien, T., \& van Heck, G. L. (2007). Relations between negative affect, coping, and emotional eating. Appetite, 48, 368-376.

Steele, C. M. (1988). The psychology of self-affirmation: Sustaining the integrity of the self. In L. Berkowitz (Ed.), Advances in experimental psychology: Social psychological studies of the self: Perspectives and programs (pp. 261-302). San Diego, CA: Academic Press. 
Steiger, J. H., \& Lind, J. C. (1980, May). Statistically-based tests for the number of common factors. Paper presented at the annual Spring meeting of the Psychometric Society, Iowa City, IA.

Stice, E. (1998). Modeling of eating pathology and social reinforcement of the thin-ideal predict onset of bulimic symptoms. Behaviour Research and Therapy, 36, 931944.

Stice, E., Fisher, M., \& Martinez, E. (2004). Eating Disorder Diagnostic Scale: Additional evidence of reliability and validity. Psychological Assessment, 16, 6071.

Stice, E., Telch, C. F., \& Rizvi, S. L. (2000). Development and validation of the Eating Disorder Diagnostic Scale: A brief self-report measure of anorexia, bulimia, and binge-eating disorder. Psychological Assessment, 12, 123-131.

Stöber, J. (1998). Worry, problem elaboration and suppression of imagery: The role of concreteness. Behaviour Research and Therapy, 36, 751-756.

Stöber, J., \& Borkovec, T. D. (2002). Reduced concreteness of worry in generalized anxiety disorder: Findings from a therapy study. Cognitive Therapy and Research, 26, 89-96.

Stöber, J., Tepperwien, S., \& Staak, M. (2000). Worrying leads to reduced concreteness of problem elaborations: Evidence for the avoidance theory of worry. Anxiety, Stress, and Coping, 13, 217-227.

Striegel-Moore, R. H., \& Franko, D. L. (2008). Should binge eating disorder be included in the DSM-IV? A critical review of the state of the evidence. Annual Review of Clinical Psychology, 4, 305-324. 
Strother, E., Lemberg, R., Stanford, S. C., \& Turberville, D. (2012). Eating disorders in men: Underdiagnosed, undertreated, and misunderstood. Eating Disorders, 20, $346-355$.

Sunday, S. R., Halmi, K. A., \& Einhorn, A. (1995). The Yale-Brown-Cornell Eating Disorder Scale: A new scale to assess eating disorder symptomatology. International Journal of Eating Disorders, 18, 237-245.

Swanson, S. A., Crow, S. J., Le Grange, D., Swendsen, J., \& Merikangas, K. R. (2011). Prevalence and correlates of eating disorders in adolescents: Results from the National Comorbidity Survey Replication Adolescent Supplement. Archives of General Psychiatry, 68, 714-723.

Tam, C. K. M., Ng, C. F. N., Yu, C. M., \& Young, B. W. Y. (2007). Disordered eating attitudes and behaviours among adolescents in Hong Kong: Prevalence and correlates. Journal of Pediatrics and Child Health, 43, 811-817.

Tobin, D. L., \& Griffing, A. S. (1995). Coping and depression in bulimia nervosa. International Journal of Eating Disorders, 18, 359-363.

Tran, V., Wiebe, D. J., Fortenberry, K. T., Butler, J. M., \& Berg, C. A. (2011). Benefit finding, affective reactions to diabetes stress, and diabetes management among early adolescents. Health Psychology, 30, 212-219.

Tucker, L. R., \& Lewis, C. (1973). A reliability coefficient for maximum likelihood factor analysis. Psychometrika, 38, 1-10.

Turner, H., \& Bryant-Waugh, R. (2004). Eating disorder not otherwise specified (EDNOS): Profiles of clients presenting at a community eating disorder service. European Eating Disorders Review, 12, 18-26. 
Tylka, T. L., \& Subich, L. M. (2002). Exploring young women's perceptions of the effectiveness and safety of maladaptive weight control techniques. Journal of Counseling \& Development, 80, 101-110.

Van Hoeken, D., Veling, W., Sinke, S., Mitchell, J. E., \& Hoek, H. W. (2009). The validity and utility of subtyping bulimia nervosa. International Journal of Eating Disorders, 42, 595-602.

Vassilopoulos, S. P. (2008). Coping strategies and anticipatory processing in high and low socially anxious individuals. Journal of Anxiety Disorders, 22, 98-107.

Verduyn, P., Van Mechelen, I., \& Tuerlinckx, F. (2011). The relation between event processing and the duration of emotional experience. Emotion, 11, 20-28.

Verplanken, B., \& Tangelder, Y. (2011). No body is perfect: The significance of habitual negative thinking about appearance for body dissatisfaction, eating disorder propensity, self-esteem and snacking. Psychology and Health, 26, 685-701.

Verplanken, B., \& Velsvik, R. (2008). Habitual negative body image thinking as psychological risk factor in adolescents. Body Image, 5, 133-140.

Watkins, E. R. (2008). Constructive and unconstructive repetitive thought. Psychological Bulletin, 134, 163-206.

Watkins, E., Moberly, N. J., \& Moulds, M. L. (2008). Processing mode causally influences emotional reactivity: Distinct effects of abstract versus concrete construal on emotional response. Emotion, 8, 364-378.

Watkins, E., \& Moulds, M. L. (2007). Reduced concreteness of rumination in depression: A pilot study. Personality and Individual Differences, 43, 1386-1395. 
Watkins, E., Moulds, M., \& Mackintosh, B. (2005). Comparisons between rumination and worry in a non-clinical population. Behaviour Research and Therapy, 43, $1577-1585$.

Wildes, J. E., Ringham, R. M., \& Marcus, M. D. (2010). Emotion avoidance in patients with anorexia nervosa: Initial test of a functional model. International Journal of Eating Disorders, 43, 398-404.

Wonderlich, S. A., Gordon, K. H., Mitchell, J. E., Crosby, R. D., \& Engel, S. G. (2009). The validity and clinical utility of binge eating disorder. International Journal of Eating Disorders, 42, 687-705.

Woolrich, R. A., Cooper, M. J., \& Turner, H. M. (2006). A preliminary study of negative self-beliefs in anorexia nervosa: A detailed exploration of their content, origins and functional links to "not eating enough" and other characteristic behaviors. Cognitive Therapy Research, 30, 735-748. 


\section{AAQ-II}

Below you will find a list of statements. Please rate how true each statement is for you by circling a number next to it. Use the scale below to make your choice.

\begin{tabular}{c|c|c|c|c|c|c}
1 & 2 & 3 & 4 & 5 & 6 & 7 \\
\hline $\begin{array}{c}\text { never } \\
\text { true }\end{array}$ & $\begin{array}{c}\text { very } \\
\text { seldom } \\
\text { true }\end{array}$ & $\begin{array}{c}\text { seldom } \\
\text { true }\end{array}$ & $\begin{array}{c}\text { sometimes } \\
\text { true }\end{array}$ & $\begin{array}{c}\text { frequently } \\
\text { true }\end{array}$ & $\begin{array}{c}\text { almost } \\
\text { always } \\
\text { true }\end{array}$ & $\begin{array}{c}\text { always } \\
\text { true }\end{array}$
\end{tabular}

1. Its OK if I remember something unpleasant.

$\begin{array}{lllllll}1 & 2 & 3 & 4 & 5 & 6 & 7\end{array}$

2. My painful experiences and memories make it difficult for me to live a life that I would value.

$\begin{array}{lllllll}1 & 2 & 3 & 4 & 5 & 6 & 7\end{array}$

3. I'm afraid of my feelings.

$\begin{array}{lllllll}1 & 2 & 3 & 4 & 5 & 6 & 7\end{array}$

4. I worry about not being able to control my worries and feelings.

$\begin{array}{lllllll}1 & 2 & 3 & 4 & 5 & 6 & 7\end{array}$

5. My painful memories prevent me from having a fulfilling life.

$\begin{array}{lllllll}1 & 2 & 3 & 4 & 5 & 6 & 7\end{array}$

6. I am in control of my life.

$\begin{array}{lllllll}1 & 2 & 3 & 4 & 5 & 6 & 7\end{array}$

7. Emotions cause problems in my life.

$\begin{array}{lllllll}1 & 2 & 3 & 4 & 5 & 6 & 7\end{array}$

8. It seems like most people are handling their lives better than I am.

$\begin{array}{lllllll}1 & 2 & 3 & 4 & 5 & 6 & 7\end{array}$

9. Worries get in the way of my success.

10 My thoughts and feelings do not get in the way of how I want to live my life. 


\section{EDDS}

\begin{tabular}{|c|c|c|c|c|c|c|c|}
\hline \multicolumn{8}{|l|}{ Please carefully complete all questions. } \\
\hline Over the past 3 months ... & $\begin{array}{c}\text { Not at } \\
\text { all }\end{array}$ & & Slightly & & Moderately & & Extremely \\
\hline 1. Have you felt fat? & 0 & 1 & 2 & 3 & 4 & 5 & 6 \\
\hline $\begin{array}{l}\text { 2. Have you had a definite fear } \\
\text { that you might gain weight or } \\
\text { become fat? }\end{array}$ & 0 & 1 & 2 & 3 & 4 & 5 & 6 \\
\hline $\begin{array}{l}\text { 3. Has your weight influenced } \\
\text { how you think about (judge) } \\
\text { yourself as a person? }\end{array}$ & 0 & 1 & 2 & 3 & 4 & 5 & 6 \\
\hline $\begin{array}{l}\text { 4. Has your shape influenced how } \\
\text { you think about (judge) } \\
\text { yourself as a person? }\end{array}$ & 0 & 1 & 2 & 3 & 4 & 5 & 6 \\
\hline
\end{tabular}

5. During the past 6 months have there been times when you felt you have eaten what other people would regard as an unusually large amount of food (e.g., a quart of ice cream) given the circumstances? YES NO

6. During the times when you ate an unusually large amount of food, did you experience a loss of control (feel you couldn't stop eating or control what or how much you were eating)? YES NO

7. How many DAYS per week on average over the past 6 MONTHS have you eaten an unusually large amount of food and experienced a loss of control? $\quad \begin{array}{lllllllll}0 & 1 & 2 & 3 & 4 & 5 & 6 & 7\end{array}$

8. How many TIMES per week on average over the past 3 MONTHS have you eaten an unusually large $\begin{array}{llllllllllll}\text { amount of food and experienced a loss of control? } & 0 & 1 & 2 & 3 & 4 & 5 & 6 & 7 & 8 & 9 & 10\end{array}$ $\begin{array}{llll}11 & 12 & 13 & 14\end{array}$

During those episodes of overeating and loss of control did you ...

9. Eat much more rapidly than normal? YES NO

10. Eat until you felt uncomfortably full? YES NO

11. Eat large amounts of food when you didn't feel physically hungry? YES NO

12. Eat alone because you were embarrassed by how much you were eating? YES NO

13. Feel disgusted with yourself, depressed, or very guilty after overeating? YES NO

14. Feel very upset about your uncontrollable overeating or resulting weight gain? YES NO

15. How many times per week on average over the past 3 months have you made yourself vomit to prevent weight gain or counteract the effects of eating? $\begin{array}{lllll}10 & 11 & 12 & 13 & 14\end{array}$

16. How many times per week on average over the past 3 months have you used laxatives or diuretics to

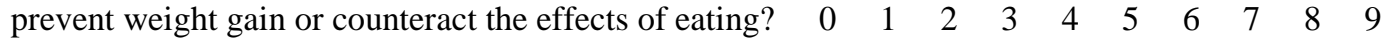
$\begin{array}{lllll}10 & 11 & 12 & 13 & 14\end{array}$

17. How many times per week on average over the past 3 months have you fasted (skipped at least 2 meals in a row) to prevent weight gain or counteract the effects of eating? $\quad \begin{array}{lllllll}0 & 1 & 2 & 3 & 4 & 5\end{array}$ $\begin{array}{lllllllll}6 & 7 & 8 & 9 & 10 & 11 & 12 & 13 & 14\end{array}$

18. How many times per week on average over the past 3 months have you engaged in excessive exercise

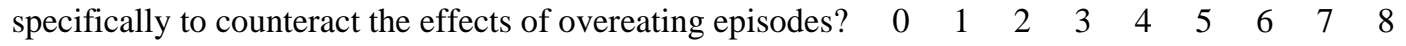
$\begin{array}{llllll}9 & 10 & 11 & 12 & 13 & 14\end{array}$ 
19. How much do you weigh? If uncertain, please give your best estimate.

lbs

20. How tall are you? $\mathrm{ft}$ in.

21. If female, over the past 3 months how many menstrual periods have you missed? $\begin{array}{llllll}0 & 1 & 2 & 3 & 4 & n a\end{array}$

22. If female, have you been taking birth control pills during the past 3 months? YES

NO 


\section{Eating Disorder Core Belief Questionnaire}

Listed below are a number of different words. People sometimes think these words describe how they feel about themselves as a person. Please read each word carefully and decide how much you feel each word describes how you feel about your own self. Base your answer on what you emotionally believe to be true, not on what you rationally believe to be true. Chose the rating that best describes what you usually believe/feel most of the time, rather than what you feel right now. If you are unsure of the meaning of a word you may skip it. Work as quickly as you can. Don't spend too long on each word - your first impression is the most important. Place a cross or a tick in the box that describes your response.

\begin{tabular}{|l|l|l|l|l|l|l|l|}
\hline & $\begin{array}{c}\text { Feels very } \\
\text { much } \\
\text { untrue }\end{array}$ & $\begin{array}{c}\text { Feels } \\
\text { moderately } \\
\text { untrue }\end{array}$ & $\begin{array}{c}\text { Feels } \\
\text { slightly } \\
\text { untrue }\end{array}$ & $\begin{array}{c}\text { Feels } \\
\text { neither true } \\
\text { nor untrue }\end{array}$ & $\begin{array}{c}\text { Feels } \\
\text { slightly } \\
\text { true }\end{array}$ & $\begin{array}{c}\text { Feels } \\
\text { moderately } \\
\text { true }\end{array}$ & $\begin{array}{c}\text { Feels very } \\
\text { much true }\end{array}$ \\
\hline Abandoned & & & & & & & \\
\hline Betrayed & & & & & & & \\
\hline Complaining & & & & & & & \\
\hline Conscientious & & & & & & & \\
\hline Demanding & & & & & & & \\
\hline Deprived & & & & & & & \\
\hline Disgraceful & & & & & & & \\
\hline Evil & & & & & & & \\
\hline Filthy & & & & & & \\
\hline Focused & & & & & & & \\
\hline Goal Oriented & & & & & & & \\
\hline Ill tempered & & & & & & & \\
\hline Immature & & & & & & & \\
\hline Inhibited & & & & & & & \\
\hline Inhuman & & & & & & & \\
\hline Manipulative & & & & & & & \\
\hline Meek & & & & & & & \\
\hline Meticulous & & & & & & & \\
\hline Misunderstood & & & & & & & \\
\hline Nasty & & & & & & & \\
\hline Needy & & & & & & & \\
\hline Painstaking & & & & & & & \\
\hline Perfectionistic & & & & & & & \\
\hline Persistent & & & & & & & \\
\hline Poisonous & & & & & & & \\
\hline Possessive & & & & & & & \\
\hline Putrid & & & & & & & \\
\hline Repugnant & & & & & & & \\
\hline Repulsive & & & & & & & \\
\hline Reserved & & & & & & & \\
\hline Self-disciplined & & & & & & & \\
\hline Selfish & & & & & & \\
\hline Submissive & & & & & & & \\
\hline Superficial & & & & & & & \\
\hline Suspicious & & & & & & & \\
\hline Unassertive & & & & & & & \\
\hline Undemonstrative & & & & & & \\
\hline Unemotional & & & & & & \\
\hline Unreflective & & & & & & & \\
\hline
\end{tabular}




\section{BAAS}

Instructions: Put a check $(\sqrt{ })$ to indicate how much you agree with each of the statements below.

\section{Interpersonal}

1. The opinion others have of me is based on my appearance.

2. The amount of influence I have on other people depends

upon how I look.

3. People will think less of me if I don't look my best.

4. People would be more interested in me if I looked better.

5. My relationships would improve if I looked the way I wished.

\section{Achievement}

6. The amount of success I have in my (future) job or career depends largely upon how I look.

7. My appearance influences my ability to do things.

8. My performance in activities (e.g., school, work, hobbies) is

influenced by how I look.

9. The opportunities that are available to me depend upon

how I look.

10. My school and/or work performance or opportunities

would improve if I looked the way I wished.

\section{Self-View}

11. My value as a person depends upon how I look.

12. How I feel about myself is largely based on my appearance.

13. I would think more highly of myself if I looked the way I wished.

14. How I look is a large part of who I am.

15. It is difficult to feel good about myself when I am not

looking my best.

Feelings

16. My ability to feel happy depends upon how I look. 


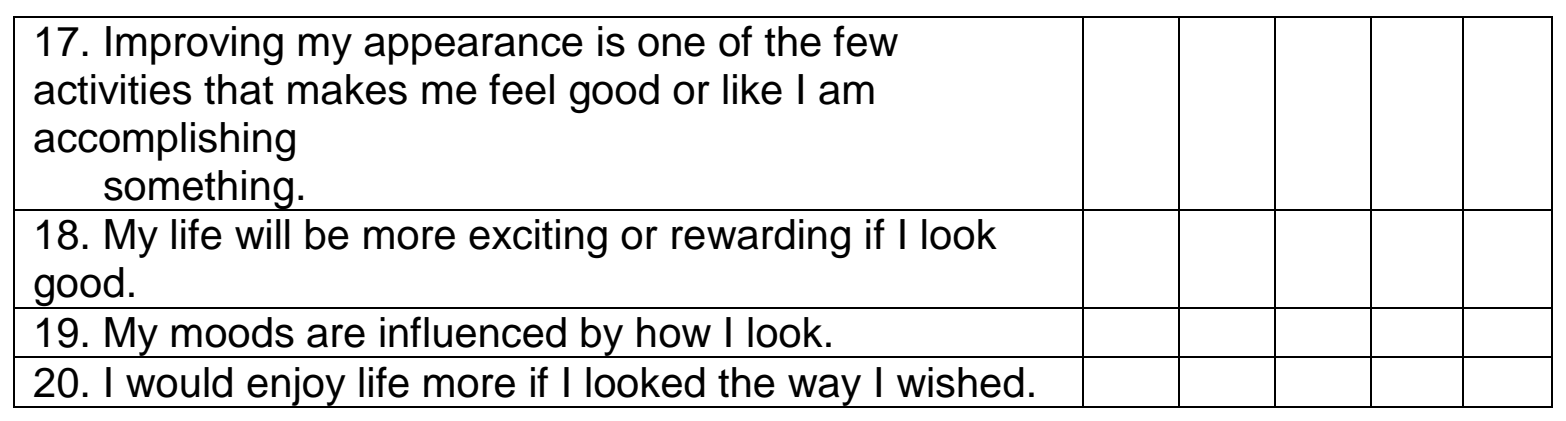

Copyright (1997 by Diane L. Spangler, Ph.D. 


\section{CURRICULUM VITAE}

\section{Anne C. Bjerg}

Office Address:

University of North Carolina at Chapel Hill

Counseling and Psychological Services

Campus Health Services

Chapel Hill, NC 27599-7470
Home Address:

105 Fidelity St., A29

Carrboro, NC 27510

913.375.0441

bjerg@email.unc.edu

Education University of Louisville, Louisville, KY

Graduate Fellow \& Doctoral Candidate

Counseling Psychology, Ph.D. Program

Advisor: Dr. Patrick Pössel

Kansas State University, Manhattan, KS

Bachelor of Science, Psychology, May 2009

\section{APA \\ Pre-Doctoral \\ Internship}

University of North Carolina at Chapel Hill, Chapel Hill, NC

Agency Type: University Counseling Center

Providing brief therapy services - approximately 8 to 10 sessions - to graduate and undergraduate students.

Running weekly Triage services to assess and refer students to appropriate treatment dispositions, with a significant focus on crisis assessment.

Member of the multidisciplinary Eating Disorder Team, meeting once weekly to consult and coordinate care across providers.

Initiated the development of a body image group for Spring 2014.

Primary facilitator for Bounce Back - a resilience-based, pscyhoeducational group focusing on academic retention.

Participating in yearlong Supervision of Supervision seminar; supervised practicum student during the Fall 2013 semester.

August 2013 - current

\section{Clinical Experience}

The Brook Hospital - KMI, Louisville, KY

Agency Type: Inpatient Psychiatric Hospital

Delivered empirically-based therapeutic services to acute adult and adolescent inpatient clients, including those suffering from eating disorders, suicidality, and substance abuse.

Led daily psychotherapy groups emphasizing DBT. 
Initiated the modeling of process groups after Yalom and Lezcz's (2011) six achievable goals for acute inpatient therapy.

Conducted intake psychosocial assessments and gathered collateral information from family and friends.

Connected clients with the appropriate community and therapy resources upon discharge.

August 2012 - May 2013

InSight Counseling, LLC., Overland Park, KS

Agency Type: Private Outpatient Clinic

Received specialized training in the treatment of eating disorders and comorbid concerns.

Co-led psychotherapy process group for adolescents.

Served as the therapist intern in nutritional counseling sessions with an on-site dietitian; delivered behavioral health services.

Worked on-call, after-hours emergency services.

Member of a multidisciplinary team, including marriage and family therapists, psychiatrists, general medical practitioners, psychologists, and dietitians.

May 2012 - August 2012

Bellarmine University Counseling Center, Louisville, KY Agency Type: University Counseling Center

Provided empirically-based therapeutic services to a student population treating a variety of concerns and diagnoses.

Conducted psychoeducational outreach seminars for academic departments and students at the university.

Served as the liaison between the counseling center and the Bellarmine School of Nursing.

Administered psychological batteries, constructed integrated reports, and provided assessment feedback with clients.

Presented cases and video recordings at weekly clinic meetings.

August 2011 - May 2012

Communicare, INC., Elizabethtown, KY

Agency Type: Community Mental Health Center

Delivered therapeutic services to individuals seeking treatment for a variety of concerns in a rural, low-income setting.

Gained experience with couples and family therapy.

Led an adult process group tailored toward anxiety management.

Co-leader of a psychoeducational group for adults diagnosed with serious mental illnesses.

Co-led an adolescent processing group focusing on social skills.

Collaborated with case managers and psychiatrists as a member of a multidisciplinary treatment team.

June 2010 - August 2011 


\section{Outreach}

Experience

University of North Carolina, Chapel Hill, NC

Instigating the development of an outreach experience with the campus LGBTQ center; services oriented toward addressing the prevalence of body image concerns within this community.

Providing outreach to various departments on campus related to sleep hygiene, stress management, and adjustment to college.

August 2013 - current

University of Louisville, Louisville, KY

Initiated the coordination, development, and implementation of outreach experiences for sorority and dormitory organizations.

Outreach tailored toward promoting healthy body image and informing students about mindful eating and diet myths.

August 2012 - December 2012

REbeL, INC., Overland Park, KS

Serving as a consultant for the non-profit, peer-education program currently running in seven high schools and one middle school in the Kansas City Metropolitan Area.

Trained students on topics of mindful eating and exercise, media literacy, the dangers of dieting, and the Health At Every Size initiative.

Continuing to develop meeting topics for students and sponsors based on current events and empirical literature.

Conducting a program evaluation of the organization to determine empirical effectiveness.

May 2012 - current

Bellarmine University, Louisville, KY

Collaborated with numerous academic departments to provide outreach services to first-year undergraduates.

Educated students on how to cope with stress, academic pressures, procrastination, and first-year transitions.

August 2011 - May 2012

Research

Experience

\section{Doctoral Dissertation}

Chair: Dr. Patrick Pössel

Title: Avoidance in disordered eating: The roles of overvaluation of weight and shape and repetitive thinking.

Dissertation Defended: August 2014

\section{Laboratory for school-based prevention of adolescent depression and promotion of academic achievement.}

Advisors: Dr. Patrick Pössel and Dr. Jill Adelson

Investigated the impact of teacher behaviors and evaluative feedback on adolescent mental health.

Developed and validated two questionnaires using student data, 
teacher data, and behavioral observations.

Personally scheduled and organized a longitudinal school-based observational study to validate two questionnaires.

Research is tailored to discovering empirically-sound preventative techniques for depression in young adults.

Incorporates cognitive constructs, including Attribution Theory.

August 2009 - May 2013

\section{Laboratory for the effects of private prayer on depressive symptoms.}

Advisor: Dr. Patrick Pössel

Researched the mechanisms of prayer across diverse religious cultures.

Investigated potential mediating roles of cognitive rumination, expectations of prayer, self-disclosure, and one's relationship with a higher being in the association between prayer and mental health.

August 2009 - May 2013

\section{Conference Presentations}

Bjerg, A. C., Pössel, P., Winkeljohn Black, S., Jeppsen, B. D., \& Wooldridge, D. T. (August, 2012). Response styles, depression, and prayer: Exploring the mediating effects. $120^{\text {th }}$ Annual APA Convention, Orlando, FL.

Jeppsen, B. D., Pössel, P., Bjerg, A. C., Winkeljohn Black, S., \& Wooldridge, D. T. (August, 2012). The power of prayer: Forming divine relationships. $120^{\text {th }}$ Annual APA Convention, Orlando, FL.

Pössel, P., Winkeljohn Black, S., Bjerg, A. C., Jeppsen, B. D., \& Wooldridge, D. T. (August, 2012). Do trust beliefs mediate the associations of frequency of prayer with mental health and wellbeing? $120^{\text {th }}$ Annual APA Convention, Orlando, FL.

Winkeljohn Black, S., Pössel, P., Jeppsen, B. D., Bjerg, A. C., \& Wooldridge, D. T. (August, 2012). The relationship between prayer frequency and psychological well-being, as mediated by prayer type. $120^{\text {th }}$ Annual APA Convention, Orlando, FL.

Wooldridge, D. T., Rudasill, K. M., Bjerg, A. C., \& Pössel, P. (April, 2011). The Teacher Behavior Questionnaire: Facilitating interventions for student success. 2011 AERA Annual Meeting, New Orleans, LA.

Bjerg, A. C. \& Pössel, P. (March, 2010). Teacher attributions of 
student success and failure: Development of a questionnaire. KPA Spring Academic Conference, Louisville, KY.

Wooldridge, D. T., Rudasill, K. M., Pössel, P., Rhyne, E. P., Busch, L. Y., \& Bjerg, A. C. (August, 2010). The Teacher Behavior Questionnaire: Facilitating interventions for student mental health. $118^{\text {th }}$ Annual APA Convention, San Diego, CA.

\section{Publications}

Awards and

Certifications
Bjerg, A. C., Pössel, P., Winkeljohn Black, S., Jeppsen, B. D., \& Wooldridge, D. T. (in preparation). Response styles, depression, and prayer: Exploring the mediating effects.

Jeppsen, B. D., Pössel, P., Bjerg, A. C., Winkeljohn Black, S., \& Wooldridge, D. T. (submitted). The power of prayer: Forming divine relationships.

Pössel, P., Rudasill, K. M., Bjerg, A. C., Sawyer, M. G., Spence, S. H., \& Sheffield, J. (submitted). Does teacher-reported school climate predict depressive symptoms in Australian high-school students?

Pössel, P., Rudasill, K. M., Sawyer, M. G., Spence, S. H., \& Bjerg, A. C. (submitted). Associations between teacher support and depression in Australian adolescents: A 5-year longitudinal study.

Pössel, P., Rudasill, K. M., Wooldridge, D. T., Bjerg, A. C., \& Winkeljohn Black, S. (submitted). The Teaching Behavior Questionnaire: Factor structure and reliability of an instrument to measure student-reported teaching behavior.

Pössel, P., Winkeljohn Black, S., Bjerg, A. C., Jeppsen, B. D., \& Wooldridge, D. T. (submitted). Do trust-based beliefs mediate the associations of frequency of private prayer with mental health? A cross-sectional study.

Winkeljohn Black, S., Pössel, P., Jeppsen, B. D., Bjerg, A. C., \& Wooldridge, D. T. (submitted). Disclosure during prayer as a mediator between prayer types and mental health.

\section{University of North Carolina at Chapel}

\section{Hill}

QPR Suicide Prevention Training

Embody Carolina Eating Disorder Ally

December 2013

October 2013

SafeZone LGBTQ Ally 


\section{University of Louisville}

University of Louisville Doctoral Dissertation Fellowship Award

August 2012 - May

2013

Professional

American Psychological Association, Student Affiliate

Affiliations

October 2009 - current

Kentucky Psychological Association, Student Affiliate

October 2009 - September 2013

\section{Consultations REbeL, INC.}

Consultant to the Board of Directors

August 2012 - current

\section{University of North Carolina at Chapel}

\section{Hill}

UNC Center of Excellence for Eating

Disorders

Group Therapy Liaison

October 2013 - current

University of Louisville

General Education Assessment Project

Inter-rater Assessment Scorer and Reviewer February 2011

Doctoral Student Candidate Interviews

Graduate Student Representative

January 2011

Guest Lecturer

Theories and Techniques of

Counseling and Psychotherapy

September 2010

\section{Committees University of North Carolina at Chapel \\ Hill}

National Eating Disorder Awareness Week

Serving as the UNC Counseling and Psychological Services

representative in collaboration with the UNC Center of Excellence for Eating Disorders.

November 2012 - current

\section{University of Louisville}

Doctoral Student Organization

Secretary, elected April 2010 - May 2012

Transcribed monthly meetings revolving around departmental events and student engagement.

$\underline{\text { Diversity Committee }}$

August 2009 - May 2013

Participated in this monthly meeting to increase competency and sensitivity to multicultural issues; evaluated articles from peer- 
reviewed journals to reflect on personal reactions and areas for growth.

\section{Curriculum Committee}

January 2010 - May 2013

Served as the student-representative, providing perspective toward adding, removing, or changing courses and study plans.

Assessment Committee

October 2009 - July 2011

Acted as a student-representative on this college-wide committee aimed at increasing ways to measure and track student academic achievement.

August 2009 - July 2011

\section{Academic Appointments}

\section{University of Louisville}

Graduate Teaching Assistant, Dept. of Educational and Counseling Psychology

Evaluation and Measurement

Co-taught principles of assessment and statistics to graduate students; assisted students in homework and test preparation.

Fall 2011, Spring 2012

Theories of Psychotherapy

Assisted in a graduate level course teaching the foundations of psychotherapy theory with an emphasis on conceptualization.

Fall 2011

Graduate Research Assistant, College of Ed. and Human

Dean's Office

Development

Collaborated across units in the college to increase departmental accountability, including helping faculty increase critical thinking components in coursework and syllabi.

August 2009 - July 2011 


\section{References}

\begin{tabular}{|c|c|c|c|}
\hline Dr. Laura Eickman & Dr. Dan Dar & & Dr. Maribel Diaz \\
\hline Director and Founder of & Psychologist & nd Intern & Psychologist and \\
\hline REbeL, INC. & Supervisor at & JNC CAPS & Coordinator \\
\hline 8400 W. 110th St., & James A. Tay & or Building & of Training at UNC CAPS \\
\hline Suite 610 & Chapel Hill, I & C 27514 & James A. Taylor Building \\
\hline Overland Park, KS 66210 & & & Chapel Hill, NC 27510 \\
\hline $913-660-4650$ & 919-966-3658 & & $919-966-3658$ \\
\hline laura.eickman@gmail.com & djdarnel@en & ail.unc.edu & msdiaz@email.unc.edu \\
\hline Dr. Jesse Owe & & Dr. Patric & össel \\
\hline Assistant Profe & ssor and & Associate P & essor and \\
\hline Director of Cli & nical Training & Academic $A$ & isor \\
\hline University of $\mathrm{L}$ & ouisville & University & Louisville \\
\hline College of Edu & cation and & College of I & Ication and \\
\hline $\begin{array}{l}\text { Human Develo } \\
\text { rm } 308\end{array}$ & pment - & $\begin{array}{l}\text { Human Der } \\
\text { rm } 330\end{array}$ & pment - \\
\hline Louisville, KY & 40292 & Louisville, & 40292 \\
\hline $502-852-0632$ & & $502-852-06$ & \\
\hline jesse.owen@lc & uisville.edu & patrick.pos & @louisville.edu \\
\hline
\end{tabular}

